\title{
Determinantes da cooperação para inovação das empresas brasileiras *
}

\author{
Ana Paula Macedo de Avellar** \\ Aderbal Oliveira Damasceno ${ }^{* * *}$ \\ Felipe Queiroz Silva ****
}

\begin{abstract}
Resumo
O objetivo desse artigo é analisar os determinantes da cooperação para inovação das empresas inovadoras brasileiras. Investiga-se os determinantes da cooperação para inovação, considerando os tipos de parceiros (cadeia produtiva, concorrentes, grupo e instituições de pesquisa), os determinantes da cooperação com o exterior e com instituições no país para inovação, considerando os tipos de parceiros. Com base nos dados da PINTEC 2011, foram estimados modelos probabilísticos para um amplo conjunto de empresas inovadoras. Os resultados sugerem que gastos com P\&D, características das empresas, apoio do governo, principais fontes de informação e obstáculos à inovação explicam a cooperação para inovação.
\end{abstract}

Palavras-chave: Cooperação, Inovação, PINTEC.

\section{Abstract}

\section{Determinants of cooperation in innovation in Brazilian firms}

The purpose of this paper is to analyze the determinants of cooperation in innovation in Brazilian innovative firms. The paper investigates the determinants of cooperation in innovation considering the types of partners, as well as the determinants of cooperation with the foreign market and with Brazilian institutions, considering the types of partners. Based on data from PINTEC 2011 probabilistic models were estimated considering a significant sample of innovative Brazilian firms. The results suggest that R\&D expenditure, firms' characteristics, government support, the main sources of information and obstacles to innovation explain the cooperation in innovation.

Keywords: Cooperation, Innovation, PINTEC.

JEL: O30, O32.

\section{Introdução}

O objetivo desse artigo é realizar uma investigação empírica sobre os determinantes da cooperação para inovação das empresas inovadoras brasileiras. Para tanto investiga-se os determinantes da cooperação para inovação, os determinantes da cooperação para inovação considerando os tipos de parceiros (outras empresas, grupo e instituições de pesquisa) e os determinantes da cooperação para inovação com o exterior e com instituições no país considerando os tipos de parceiros (outras empresas, grupo e instituições de pesquisa).

Com base nos dados da PINTEC 2011, estima-se modelos probabilísticos para um amplo conjunto de empresas inovadoras brasileiras. Os resultados encontrados sugerem o seguinte padrão geral: $\mathrm{O}$ aumento do gasto com $\mathrm{P} \& \mathrm{D}$, do tamanho da empresa, da qualificação da mãode-obra, ter capital estrangeiro, participar de grupo, receber apoio do governo e considerar as

\footnotetext{
* Artigo recebido em 31 de março de 2020 e aprovado em 26 de junho de 2020.

${ }^{* *}$ Professora Associada do Instituto de Economia e Relações Internacionais da Universidade Federal de Uberlândia (IERIUFU), Uberlândia, MG, Brasil. E-mail: anaavellar@ufu.br. ORCID: https://orcid.org/0000-0001-8455-9458.

${ }^{* * *}$ Professor Associado do Instituto de Economia e Relações Internacionais da Universidade Federal de Uberlândia (IERI/UFU). E-mail: aderbal.damasceno@ufu.br. ORCID: https://orcid.org/0000-0002-6289-6805.

***** Professor Adjunto da Faculdade de Administração, Ciências Contábeis e Ciências Econômicas da Universidade Federal de Goiás (FACE/UFG). E-mail: felipe.queiroz@ufg.br. ORCID: https://orcid.org/0000-0003-4246-3292.
} 
instituições de pesquisa importante fonte de informação aumentam a probabilidade de cooperação para inovação das empresas brasileiras.

Nas últimas décadas, com a intensificação do processo concorrencial, a aceleração do ritmo inovativo e a emergência do conceito de Sistema Nacional de Inovação, intensificaram-se as atividades de cooperação para inovação. Nesse contexto, as empresas constatam que seu conhecimento interno deixou de ser suficiente para a obtenção de uma inserção inovadora no mercado. Assim, as atividades de cooperação para inovação passam a representar oportunidades de acesso a conhecimento e a recursos tecnológicos complementares, bem como ao compartilhamento de custos e riscos. (Veugelers; Cassiman, 1999; Theter, 2002; Cassiman; Veugelers, 1999; 2002).

Vale ressaltar a importância de se estudar experiências de cooperação para inovação em países em desenvolvimento, como o caso brasileiro, dada a necessidade de se identificar suas especificidades em relação aos países desenvolvidos. Ademais, as evidências encontradas nesse estudo empírico podem auxiliar no desenho de políticas industriais e de inovação que estimulem, de maneira mais precisa, o desenvolvimento inovativo no país.

Diversos estudos empíricos investigam os motivos que levam as empresas a optarem pelas atividades de cooperação para inovação, seja com o grupo de empresas que participa, com outras empresas rivais, com instituições de pesquisa, com clientes e fornecedores, no país ou no exterior. A análise dos determinantes da cooperação internacional para inovação vem crescendo dentre os estudos sobre o tema. Com o aumento da inserção internacional das empresas, a parceria com exterior para o desenvolvimento de inovação passou a ser mais uma importante fonte para absorção de novos conhecimentos.

A literatura sobre os determinantes da cooperação para inovação das empresas brasileiras é relativamente escassa. Desse modo, o trabalho contribui para a literatura em aspectos relevantes, ao investigar os determinantes da cooperação, considerando o tipo de parceiro e a sua localidade (Brasil e exterior). Deste modo, o trabalho avança no debate empírico para as empresas brasileiras em três aspectos, ao investigar: i) os determinantes da cooperação para inovação das empresas brasileiras e se os determinantes da cooperação para inovação das empresas brasileiras são distintos por tipo de parceiro; ii) os determinantes da cooperação com o exterior para inovação das empresas brasileiras e se os determinantes da cooperação com o exterior para inovação das empresas brasileiras são distintos por tipo de parceiro; iii) os determinantes da cooperação no país para inovação das empresas brasileiras e se os determinantes da cooperação no país para inovação das empresas brasileiras são distintos por tipo de parceiro.

O artigo está dividido em quatro seções. A seção 1 desenvolve uma breve revisão da literatura teórica e empírica sobre cooperação para inovação. Na seção 2 são apresentados os procedimentos metodológicos, com a descrição das variáveis e a metodologia utilizada neste estudo. A seção 3 apresenta as características das empresas analisadas e os resultados obtidos no estudo. E, finalmente, faz-se algumas considerações finais.

\section{Revisão da literatura teórica e empírica}

A inovação pode ser entendida como o resultado da interação entre agentes e instituições, sendo a cooperação para inovação uma importante alternativa para a empresa obter conhecimento tecnológico externo e, com isso, aprimorar seu posicionamento no mercado, em consonância com a abordagem de Sistema Nacional de Inovação (Lundvall, 1992; Nelson, 1993; Dosi; Cimoli, 
1994). Nesse sentido, a empresa não se torna inovadora atuando de maneira isolada, sendo a inovação considerada cada vez mais o resultado de uma combinação de uma multiplicidade de atores e fontes.

Com base na discussão sobre a importância das articulações entre um conjunto diverso de agentes, tais como instituições de pesquisa e setor produtivo, Suzigan e Albuquerque (2008) exaltam o importante papel das parcerias, essencialmente o das instituições de pesquisa na capacitação de recursos humanos, como fonte de pesquisa básica, destacando o estabelecimento de canais para absorção de conhecimento.

A partir de 1990 alguns estudos passaram a utilizar de análise empírica para investigar com o comportamento de cooperação das empresas, em grande medida viabilizado pela disponibilidade de base de dados por empresa (OECD, 2009; OECD, 2010; Hagedoorn, 2001). Para compreender quais fatores determinam a decisão de cooperar para inovação, diversos estudos empíricos foram desenvolvidos durante os anos 2000. A maioria desses trabalhos tem como objetivo analisar os motivos da cooperação para inovação e encontrar evidências de que para as empresas que cooperam, os esforços internos em atividades inovativas podem ser complementados com o conhecimento absorvido do ambiente externo (Cassiman; Veugelers, 1999, 2002; Negassi, 2004; Okamuro et al., 2010; Kupfer; Avellar, 2009; Faria et al., 2010).

Trabalhos pioneiros sobre esse tema foram desenvolvidos por Mowery (1989) e Hagedoorn (1993). Mowery (1989) investiga a atividade de cooperação da indústria manufatureira dos Estados Unidos com parceiros internacionais. Dentre os resultados encontrados, evidencia uma grande diferença das caraterísticas da cooperação entre os diferentes setores industriais, concluindo também sobre a importância das políticas públicas no estímulo à inovação das empresas nacionais.

Hagedoorn (1993), por sua vez, sistematiza os motivos de uma empresa realizar cooperação para inovação. Para o autor, os motivos que levam as empresas a buscarem a cooperação para inovar são: i) motivos relacionados à pesquisa básica e aplicada, tais como redução de incerteza e compartilhamento de custos de $\mathrm{P} \& \mathrm{D}$; ii) motivos relacionados ao processo de inovação em si, como a captura de conhecimento tácito do parceiro de tecnologia, transferência de tecnologia e redução do ciclo de vida do produto; iii) motivos relacionados ao acesso ao mercado e busca de novas oportunidades.

Além dos três conjuntos de motivações discutidas por Hagedoorn (1993), Tether (2002) argumenta que a cooperação para a inovação está mais relacionada ao tipo de inovação que as empresas realizam do que com suas características. Em seu estudo, o autor analisa empresas inovadoras no Reino Unido e encontra evidências de que as empresas que realizam inovações radicais estão mais aptas a realizarem atividades de cooperação do que as empresas que desenvolvem inovação do tipo incremental.

Ademais, a literatura sobre o tema investiga se as características das empresas e do setor industrial influenciam na decisão de cooperação para inovação das empresas. Veugelers e Cassiman (1999) encontram evidências, para empresas na Bélgica, que as empresas de grande porte (mais de 500 funcionários) apresentam maior probabilidade de realizarem internamente as atividades inovativas e de absorverem conhecimento externo por meio de parcerias, utilizando a cooperação como uma estratégia de complementaridade de conhecimento. As empresas de pequeno porte, por sua vez, são mais propensas a realizarem atividades inovadoras internas ou adquirirem o conhecimento externamente, como estratégias excludentes. $\mathrm{O}$ setor industrial 
também pode ser considerado uma variável que determina a decisão de cooperação para inovação das empresas, pois estão relacionadas às oportunidades tecnológicas das empresas e à cumulatividade do conhecimento (Veugelers; Cassiman, 1999; Tether, 2002).

Alguns trabalhos investigam se a apropriabilidade do conhecimento explica a probabilidade de a empresa realizar cooperação para inovação. Cassiman e Veugelers (2002) criam um indicador de apropriabilidade com base em dois tipos de proteção: proteção legal (patentes e direitos autorais) e proteção estratégica (sigilo e complexidade da tecnologia). A partir de uma amostra de 411 empresas da Bélgica, os resultados dos modelos probabilísticos sugerem que quanto mais desenvolvida a capacidade de apropriação de uma empresa maior a probabilidade de a empresa cooperar com clientes e fornecedores. Esse resultado indica que as empresas que conseguem assegurar o conhecimento gerado internamente, com algum tipo de proteção, estão mais dispostas a complementarem seu conhecimento interno com o externo por meio de parcerias.

Cassiman e Veugelers (2002) avançam em relação a Veugelers e Cassiman (1999) e contribuem para o debate ao testarem a hipótese de que a decisão de cooperar para inovação é tomada com base no fluxo de informações que entra e sai da empresa. O principal argumento desses autores é o da complementaridade (ou substituição) entre recursos tecnológicos internos e externos, ou seja, a empresa necessita escolher entre "fazer ou comprar" ou "fazer e comprar" atividades inovativas. Constroem um modelo para identificar em que medida as variáveis "spillovers de entrada" e "variável apropriabilidade" afetam a probabilidade de uma empresa para cooperar com atividades inovadoras. A partir de uma amostra de 411 empresas da Bélgica, os resultados encontrados sugerem que as empresas mais propensas a cooperar são aquelas que têm mais capacidade para acumular e utilizar a experiência externa. Esse debate sobre a complementaridade dos conhecimentos tecnológicos internos e externos é baseado no conceito de "capacidade de absorção", desenvolvido por Cohen e Levinthal (1989), que definem que a capacidade de uma empresa de incorporar e utilizar com sucesso o fluxo de informações advindas das parcerias é maior quanto mais conhecimento e capacidades internas essa empresa possui.

Uma questão também investigada na literatura se refere ao papel exercido pelas políticas de apoio do governo nas decisões das empresas cooperarem para inovação. Negassi (2004) realiza um estudo econométrico para uma amostra composta de 3.801 empresas da França, entre os anos 1990 e 1996, e os resultados encontrados dos modelos probabilísticos estimados sugerem que receber apoio do governo para a realização de atividades inovativas aumenta a probabilidade de a empresa cooperar para inovação.

Alguns estudos internacionais analisam o comportamento da cooperação para inovação considerando um recorte setorial. Badillo, Galera e Serrano (2017) analisam a cooperação em P\&D na indústria automobilística na Espanha. O primeiro objetivo do estudo é examinar os determinantes da decisão de cooperação para inovação pelas empresas e, com que tipo de parceiro de cooperação. O segundo objetivo é estudar como o tamanho da empresa afeta a decisão de cooperar e o tipo de parceiro. Os dados deste estudo foram extraídos de pesquisas realizadas em 2010 e 2013 pelo Painel de Inovação Tecnológica (PITEC) para empresas do setor automotivo. Foi estimado um modelo probit bivariado considerando os dois tipos de cooperação mais recorrentes no setor: vertical e institucional. Por cooperação vertical define-se a cooperação com fornecedores e / ou clientes, enquanto que por cooperação institucional considera-se a cooperação 
com consultorias, laboratórios ou institutos particulares de $\mathrm{P} \& \mathrm{D}$, universidades ou outras instituições de ensino superior e organizações públicas de pesquisa. Os resultados encontrados apontam que as pequenas empresas cooperam com menos frequência do que as grandes e que dar mais importância às informações publicamente disponíveis, e ter apoio financeiro público dos governos locais e nacionais são determinantes importantes dos acordos de colaboração.

Além desse conjunto de trabalhos que investigam os determinantes da cooperação para inovação, uma importante questão é inserida nos estudos empíricos, qual seja, a importância do tipo de parceiro na realização de atividades de cooperação para inovação. Schmidt (2005) analisa os determinantes de cooperação para inovação para uma amostra de empresas da Alemanha. Os resultados dos modelos probabilísticos sugerem uma relação positiva entre o fluxo de conhecimento e atividades de cooperação. Ao desagregar a análise por tipo de parceiro, os resultados apontam que as empresas com maior capacidade de inovação interna são mais propensas a cooperar com universidades e instituições de pesquisa do que com os fornecedores ou clientes.

Belderbos et al. (2005) também analisam a importância do tipo de parceiro, como um elemento importante para entender as motivações das empresas para a cooperação em $\mathrm{P} \& \mathrm{D}$. Com base em uma amostra de 1763 empresas francesas inovadoras, os resultados dos modelos probabilísticos sugerem que as empresas que colaboram com concorrentes e fornecedores estão focadas na inovação incremental, enquanto as empresas que cooperam com universidades e centros de pesquisa concentram-se na inovação radical para aumentar as vendas de produtos e serviços do mercado.

Faria et al. (2010) analisam para empresas portuguesas, no período de 1998 a 2000, quais os determinantes da probabilidade de cooperar. Para a amostra total de empresas, os resultados dos modelos probabilísticos sugerem que o tamanho da empresa, qualificação da mão-de-obra, participação das exportações, fazer parte de grupo, gastos em P\&D e apropriabilidade têm impacto positivo sobre a probabilidade de as empresas cooperarem. Ao se considerar somente o subgrupo de empresas que dão elevada importância à cooperação, constata-se que empresas com altos níveis de capacidade de absorção (incoming knowledge spillovers) e investimento em inovação, dão maior importância aos ganhos com spillovers. Observa-se também que empresas que cooperam com outras empresas do grupo e com fornecedores valorizam mais a cooperação no processo inovativo.

Okamuro et al. (2011) desenvolvem um estudo com objetivo de analisar os determinantes da cooperação em atividades de $\mathrm{P} \& \mathrm{D}$ com outras empresas e com Universidades nas novas empresas (start-up) no Japão. Desenvolvem um modelo probabilístico considerando 3 aspectos: i) características do fundador; ii) características da empresa e iii) características da indústria. Os resultados encontrados sugerem que as características do fundador da empresa determinam a probabilidade da empresa cooperar em P\&D. No que tange à cooperação com Universidades: i) qualificação, experiência anterior com inovação e filiação em associação acadêmica afetam positivamente a probabilidade de cooperar; ii) gastos em P\&D afetam positivamente a probabilidade de cooperar; iii) ser empresa independente afeta negativamente a probabilidade de cooperar e iv) grau de apropriabilidade afeta positivamente a probabilidade de cooperar. Quanto à cooperação com empresas, os resultados apontam: i) a existência de relação prévia com 
inovação e experiência profissional afetam positivamente a probabilidade de cooperar com outras empresas, e ii) gastos em $\mathrm{P} \& \mathrm{D}$ afetam positivamente a probabilidade de cooperar.

Henttonen e Hurmelinna-Laukkanen (2014) discutem como os determinantes da cooperação para inovação de empresas na Finlândia variam entre parceiros. O estudo empírico baseia-se em uma base de dados inédita, cujos dados foram coletados de 197 empresas por meio de um survey realizado em 2008 e 2009. Dentre os resultados encontrados verifica-se que, em consonância com Veugelers e Cassiman (1999), as empresas maiores estão melhor equipadas e dispostas a colaborar com vários parceiros em suas atividades de P\&D. Outra evidência importante encontrada nesse estudo é que quanto mais a empresa absorver e considerar importante as informações advindas de universidades e instituições de pesquisa, maior é seu interesse em colaborar com essas organizações.

Outra temática desenvolvida na literatura internacional recente e também investigada nesse estudo se refere aos acordos de cooperação internacionais, estabelecidos com parceiros no exterior. Faria e Schmidt (2007) investigam as motivações para as empresas portuguesas e alemãs escolherem cooperar com parceiros estrangeiros para realização de atividades inovativas. Os resultados dos modelos probabilísticos indicam que as empresas que possuem alguma inserção externa e capital estrangeiro são mais propensas a cooperar com parceiros estrangeiros.

Arvanitis e Bolli (2013) analisam os determinantes da cooperação para inovação com agentes nacionais e internacionais em cinco países europeus: Bélgica, Alemanha, Noruega, Portugal e Suíça. A base de dados utilizada é a Community Innovation Survey (CIS3), referente aos anos 1998-2000, para os países membros da União Europeia e Noruega, e para a Suíça os dados utilizados foram coletados de um survey compatível com a CIS3. Estimam modelos probabilísticos utilizando uma variável dummy para indicar se a empresa realiza cooperação nacional ou internacional. Eles encontram evidências de que mesmo diante de uma amostra heterogênea de países, encontra-se um padrão nos resultados: capacidade de absorção (gastos em P\&D em relação à receita, qualificação da mão-de-obra), relevância das fontes de informação externas (incoming spillovers) e alta apropriabilidade são determinantes da decisão de cooperação para inovação tanto com agentes nacionais quanto internacionais, sendo os efeitos para a cooperação internacional de maior magnitude.

Para países em desenvolvimento, especialmente o Brasil, poucos trabalhos foram desenvolvidos e, dadas as especificidades da cooperação para inovação em países em desenvolvimento, a temática do presente estudo ganha ainda mais relevância (Suzigan et al, 2011; Pinho e Fernandes, 2015). Kupfer e Avellar (2009) analisam os determinantes da cooperação para inovação das empresas brasileiras. Com base em dados da PINTEC (2005) estimam modelos probabilísticos para empresas inovadoras da indústria manufatureira. Dentre os resultados encontrados, observam que o aumento do tamanho, ter capital estrangeiro, realizar diferenciação de produtos, obter informação na infraestrutura de $\mathrm{C} \& \mathrm{~T}$ e enfrentar problemas com qualificação da mão-de-obra aumentam a probabilidade de cooperar para inovação. Bastos e Britto (2017) desenvolvem um estudo empírico sobre cooperação de empresas no Brasil, com base em dados da PINTEC (2011). Dentre os resultados encontrados constata-se a existência de um padrão de interação complexo, sendo a intensidade das relações de cooperação influenciadas pelo porte e 
origem de capital. Ademais, evidenciam também uma intensificação da adoração de estratégias de cooperação entre empresas no país.

Um recente estudo sobre a cooperação em $P \& D$ entre universidade-empresa no Brasil foi desenvolvido por de Moraes et al. (2018). O objetivo desse estudo é avaliar os determinantes da cooperação em $\mathrm{P} \& \mathrm{D}$ entre indústria e universidade no Brasil considerando o recorte setorial. A análise empírica baseia-se nos dados da Pesquisa de Inovação (PINTEC 2011) e na estimação de modelos econométricos. As variáveis utilizadas agregam-se em três dimensões: a) capacidades internas das empresas (tamanho, P\&D intramural, $\mathrm{P} \& \mathrm{D}$ extramural, inovação de produto, inovação de processo); b) estrutura de incentivo de interações (financiamento do governo); c) estrutura contextual de condições (risco econômico, custo da inovação). Dentre os resultados encontrados, verifica-se que para a maioria dos setores do país, os principais determinantes são tamanho, P\&D extramural e inovação de produtos. Ao incluir outliers na análise, os determinantes da cooperação passam a ser tamanho, $P \& D$ intramural e financiamento do governo, sugerindo a existência do efeito da capacidade de absorção quando os setores avançados do país são considerados na análise.

Considerando a escassez de trabalhos empíricos sobre os determinantes da cooperação para inovação para empresas de países em desenvolvimento, especialmente para empresas do Brasil, esse trabalho contribui para a literatura em aspectos relevantes, ao investigar: i) os determinantes da cooperação para inovação das empresas brasileiras e se os determinantes da cooperação para inovação das empresas brasileiras são distintos por tipo de parceiro; ii) os determinantes da cooperação com o exterior para inovação das empresas brasileiras e se os determinantes da cooperação com o exterior para inovação das empresas brasileiras são distintos por tipo de parceiro; iii) os determinantes da cooperação no Brasil para inovação das empresas e se os determinantes da cooperação no país para inovação das empresas brasileiras são distintos por tipo de parceiro.

\section{Procedimentos metodológicos}

\subsection{Dados}

Para a realização desse estudo empírico foram utilizados os dados da Pesquisa de Inovação (PINTEC 2011), referente aos anos de 2009 a 2011, realizada pelo Instituto Brasileiro de Geografia e Estatística (IBGE). O Quadro 1 descreve as variáveis dependentes e o Quadro 2 as variáveis explanatórias utilizadas nos modelos probabilísticos.

O Quadro 1 apresenta as variáveis dependentes binárias: A) Cooperação (no Brasil e no Exterior): i) Cooperação; ii) Cooperação com Cadeia Produtiva; iii) Cooperação com Concorrentes; iv) Cooperação com Grupo; v) Cooperação com Instituições de Pesquisa; B) Cooperação no Exterior: vi) Cooperação no Exterior; vii) Cooperação com Cadeia Produtiva no Exterior; viii) Cooperação com Concorrentes no Exterior, ix) Cooperação com Grupo no Exterior; x) Cooperação com Instituições de Pesquisa no Exterior; C) Cooperação no Brasil: xi) Cooperação no Brasil; xii) Cooperação com Cadeia Produtiva no Brasil; xiii) Cooperação com Concorrentes no Brasil, xiv) Cooperação com Grupo no Brasil; xv) Cooperação com Instituições de Pesquisa no Brasil. 
Quadro 1

Descrição das variáveis dependentes

\begin{tabular}{|c|c|c|}
\hline Código & Nome da Variável & Descrição \\
\hline \multicolumn{3}{|c|}{ i) Cooperação (no Brasil e no Exterior) } \\
\hline Coop & Cooperação & $\begin{array}{l}\text { Variável Binária, que recebe valor unitário caso a firma esteve envolvida em } \\
\text { arranjos cooperativos com outra(s) organização(ões) com vistas a } \\
\text { desenvolver atividades inovativas (entre } 2009 \text { e 2011). }\end{array}$ \\
\hline CoopCad & $\begin{array}{l}\text { Cooperação com } \\
\text { Cadeia Produtiva }\end{array}$ & $\begin{array}{l}\text { Variável Binária, que recebe valor unitário caso a firma aponte que seu } \\
\text { parceiro cooperativo com empresas da cadeia produtiva (clientes ou } \\
\text { fornecedores) é de alta ou média importância para o processo de inovação } \\
\text { (entre } 2009 \text { e 2011). }\end{array}$ \\
\hline CoopConc & $\begin{array}{l}\text { Cooperação com } \\
\text { Concorrentes }\end{array}$ & $\begin{array}{l}\text { Variável Binária, que recebe valor unitário caso a firma aponte que seu } \\
\text { parceiro cooperativo com concorrentes é de alta ou média importância para } \\
\text { o processo de inovação (entre } 2009 \text { e 2011). }\end{array}$ \\
\hline CoopGru & $\begin{array}{l}\text { Cooperação com } \\
\text { Grupo }\end{array}$ & $\begin{array}{l}\text { Variável Binária, que recebe valor unitário caso a firma aponte que seu } \\
\text { parceiro cooperativo com empresas do mesmo grupo é de alta ou média } \\
\text { importância para o processo de inovação (entre } 2009 \text { e 2011). }\end{array}$ \\
\hline CoopPesq & $\begin{array}{l}\text { Cooperação com } \\
\text { Instituições de } \\
\text { Pesquisa }\end{array}$ & $\begin{array}{l}\text { Variável Binária, que recebe valor unitário caso a firma aponte que seu } \\
\text { parceiro cooperativo com instituições de pesquisa é de alta ou média } \\
\text { importância para o processo de inovação (entre } 2009 \text { e 2011). }\end{array}$ \\
\hline \multicolumn{3}{|c|}{ ii) Cooperação no Exterior } \\
\hline CoopExt & $\begin{array}{l}\text { Cooperação no } \\
\text { Exterior }\end{array}$ & $\begin{array}{l}\text { Variável Binária, que recebe valor unitário caso a firma aponte que seu } \\
\text { principal parceiro cooperativo para o processo inovativo está localizado no } \\
\text { exterior (entre } 2009 \text { e 2011). }\end{array}$ \\
\hline CoopCadExt & $\begin{array}{l}\text { Cooperação com } \\
\text { Cadeia Produtiva no } \\
\text { Exterior }\end{array}$ & $\begin{array}{l}\text { Variável Binária, que recebe valor unitário caso a firma aponte que seu } \\
\text { principal parceiro cooperativo com outras empresas está localizado no } \\
\text { exterior (entre } 2009 \text { e 2011). }\end{array}$ \\
\hline CoopConcExt & $\begin{array}{l}\text { Cooperação com } \\
\text { Concorrentes no } \\
\text { Exterior }\end{array}$ & $\begin{array}{l}\text { Variável Binária, que recebe valor unitário caso a firma aponte que seu } \\
\text { parceiro cooperativo com concorrentes está localizado no exterior (entre } \\
2009 \text { e 2011). }\end{array}$ \\
\hline CoopGruExt & $\begin{array}{l}\text { Cooperação com } \\
\text { Grupo no Exterior }\end{array}$ & $\begin{array}{l}\text { Variável Binária, que recebe valor unitário caso a firma aponte que seu } \\
\text { principal parceiro cooperativo com empresas do mesmo grupo está } \\
\text { localizado no exterior (entre } 2009 \text { e 2011). }\end{array}$ \\
\hline CoopPesqExt & $\begin{array}{l}\text { Cooperação com } \\
\text { Instituições de } \\
\text { Pesquisa no Exterior }\end{array}$ & $\begin{array}{l}\text { Variável Binária, que recebe valor unitário caso a firma aponte que seu } \\
\text { principal parceiro cooperativo com instituições de pesquisa está localizado } \\
\text { no exterior (entre 2009 e 2011). }\end{array}$ \\
\hline \multicolumn{3}{|c|}{ iii) Cooperação no Brasil } \\
\hline CoopBra & Cooperação no Brasil & $\begin{array}{l}\text { Variável Binária, que recebe valor unitário caso a firma aponte que seu } \\
\text { principal parceiro cooperativo para o processo inovativo está localizado no } \\
\text { Brasil (entre 2009 e 2011). }\end{array}$ \\
\hline CoopCadBra & $\begin{array}{l}\text { Cooperação com } \\
\text { Cadeia Produtiva no } \\
\text { Brasil }\end{array}$ & $\begin{array}{l}\text { Variável Binária, que recebe valor unitário caso a firma aponte que seu } \\
\text { principal parceiro cooperativo com outras empresas está localizado no Brasil } \\
\text { (entre } 2009 \text { e 2011). }\end{array}$ \\
\hline CoopConcBra & $\begin{array}{l}\text { Cooperação com } \\
\text { Concorrentes no } \\
\text { Brasil }\end{array}$ & $\begin{array}{l}\text { Variável Binária, que recebe valor unitário caso a firma aponte que seu } \\
\text { parceiro cooperativo com concorrentes está localizado no Brasil (entre } 2009 \\
\text { e 2011). }\end{array}$ \\
\hline CoopGruBra & $\begin{array}{l}\text { Cooperação com } \\
\text { Grupo no Brasil }\end{array}$ & $\begin{array}{l}\text { Variável Binária, que recebe valor unitário caso a firma aponte que seu } \\
\text { principal parceiro cooperativo com empresas do mesmo grupo está } \\
\text { localizado no Brasil (entre } 2009 \text { e 2011). }\end{array}$ \\
\hline CoopPesqBra & $\begin{array}{l}\text { Cooperação com } \\
\text { Instituições de } \\
\text { Pesquisa no Brasil }\end{array}$ & $\begin{array}{l}\text { Variável Binária, que recebe valor unitário caso a firma aponte que seu } \\
\text { principal parceiro cooperativo com instituições de pesquisa está localizado } \\
\text { no Brasil (entre } 2009 \text { e 2011). }\end{array}$ \\
\hline
\end{tabular}

As variáveis explanatórias apresentadas no Quadro 2 estão agrupadas em oito categorias: i) características das empresas (pessoal ocupado, grupo e capital estrangeiro), ii) esforço inovativo (gastos com pesquisa e desenvolvimento), iii) capacitação tecnológica (qualidade de mão-de-obra e P\&D contínuo), iv) apoio do governo, v) principais fontes de informação utilizadas pelas empresas, vi) obstáculos à inovação, vii) intensidade tecnológica do setor industrial e viii) região geográfica. As variáveis explanatórias selecionadas coincidem com as utilizadas nos estudos empíricos apresentados (Belderbos et al., 2005; Faria et al., 2010; Okamuro et al., 2011; Bastos; Britto, 2017), que, por sua vez, fundamentam-se na discussão desenvolvida ao longo do referencial teórico do presente estudo. 
Quadro 2

Descrição das variáveis explanatórias

\begin{tabular}{|c|c|c|}
\hline Código & Nome da Variável & Descrição \\
\hline \multicolumn{3}{|c|}{ i) Características da Empresa } \\
\hline $\mathrm{PO}$ & Pessoal Ocupado & Logaritmo do Número de Trabalhadores em 2011. \\
\hline Grupo & Grupo & $\begin{array}{l}\text { Variável Binária, que recebe valor unitário caso a firma faça parte de um } \\
\text { grupo. }\end{array}$ \\
\hline Capest & Capital Estrangeiro & $\begin{array}{l}\text { Variável Binária, que recebe valor unitário caso a origem do capital } \\
\text { controlador da firma é estrangeiro ou misto. }\end{array}$ \\
\hline \multicolumn{3}{|c|}{ ii) Indicadores de Esforço Inovativo } \\
\hline $\operatorname{lnGPD}$ & $\begin{array}{l}\text { Gasto com } \\
\text { Pesquisa e } \\
\text { Desenvolvimento }\end{array}$ & $\begin{array}{l}\text { Logaritmo do Valor do investimento total em P\&D no ano de } 2011 \text { (em } \\
\text { Reais). }\end{array}$ \\
\hline \multicolumn{3}{|c|}{ iii) Indicadores de Capacitação Tecnológica } \\
\hline Skill & $\begin{array}{l}\text { Qualificação da } \\
\text { mão-de-obra }\end{array}$ & $\begin{array}{l}\text { Variável Binária, que recebe valor unitário caso a firma possua mão-de-obra } \\
\text { com nível de qualificação superior nas atividades internas de P\&D. }\end{array}$ \\
\hline Pdcont & P\&D Contínuo & $\begin{array}{l}\text { Variável Binária, que recebe valor unitário caso a firma tenha realizado } \\
\text { investimentos de } P \& D \text { de forma contínua. }\end{array}$ \\
\hline \multicolumn{3}{|c|}{ iv) Apoio do Governo } \\
\hline Gov & Apoio do Governo & $\begin{array}{l}\text { Varável Binária, que recebe valor unitário caso a firma utilize algum } \\
\text { programa de apoio do governo para as atividades inovativas (entre } 2009 \text { e } \\
\text { 2011). }\end{array}$ \\
\hline \multicolumn{3}{|c|}{ v) Fontes de Informação } \\
\hline Infconc & $\begin{array}{l}\text { Fonte de } \\
\text { Informação com } \\
\text { Concorrente }\end{array}$ & $\begin{array}{l}\text { Variável Binária, que recebe valor unitário caso a firma aponte concorrentes } \\
\text { como sendo de alta ou média importância para o processo de inovação (entre } \\
2009 \text { e 2011). }\end{array}$ \\
\hline Infcad & $\begin{array}{l}\text { Fonte de } \\
\text { Informação com a } \\
\text { Cadeia Produtiva }\end{array}$ & $\begin{array}{l}\text { Variável Binária, que recebe valor unitário caso a firma aponte fontes de } \\
\text { informação relacionadas à cadeia produtiva (interna, com grupo, com } \\
\text { fornecedores, com clientes e/ou com consultores) como sendo de alta ou } \\
\text { média importância para o processo de inovação (entre } 2009 \text { e 2011). }\end{array}$ \\
\hline Infpesq & $\begin{array}{l}\text { Fonte de } \\
\text { Informação com } \\
\text { Centros de } \\
\text { Pesquisa }\end{array}$ & $\begin{array}{l}\text { Variável Binária, que recebe valor unitário caso a firma aponte centros } \\
\text { educacionais e de pesquisa como sendo de alta ou média importância para o } \\
\text { processo de inovação (entre } 2009 \text { e } 2011 \text { ). }\end{array}$ \\
\hline \multicolumn{3}{|c|}{ vi) Obstáculos à Inovação } \\
\hline Obsfinan & $\begin{array}{l}\text { Obstáculo no } \\
\text { acesso ao } \\
\text { financiamento }\end{array}$ & $\begin{array}{l}\text { Variável Binária, que recebe valor unitário caso a firma aponte que } \\
\text { obstáculos referentes à escassez de fontes apropriadas de financiamento } \\
\text { obtiveram alta ou média importância para o desenvolvimento de atividades } \\
\text { inovativas (entre } 2009 \text { e 2011). }\end{array}$ \\
\hline Obsorg & $\begin{array}{l}\text { Obstáculo } \\
\text { organizacional }\end{array}$ & $\begin{array}{l}\text { Variável Binária, que recebe valor unitário caso a firma aponte que } \\
\text { obstáculos referentes à rigidez organizacional obtiveram alta ou média } \\
\text { importância para o desenvolvimento de atividades inovativas (entre } 2009 \text { e } \\
\text { 2011). }\end{array}$ \\
\hline Obsqual & $\begin{array}{l}\text { Obstáculo } \\
\text { qualificacao } \\
\text { pessoal }\end{array}$ & $\begin{array}{l}\text { Variável Binária, que recebe valor unitário caso a firma aponte que } \\
\text { obstáculos referentes à falta de pessoal qualificado obtiveram alta ou média } \\
\text { importância para o desenvolvimento de atividades inovativas (entre } 2009 \text { e } \\
\text { 2011). }\end{array}$ \\
\hline Obstec & $\begin{array}{l}\text { Obstáculo no } \\
\text { acesso à tecnologia }\end{array}$ & $\begin{array}{l}\text { Variável Binária, que recebe valor unitário caso a firma aponte que } \\
\text { obstáculos referentes à falta de informação sobre tecnologia obtiveram alta } \\
\text { ou média importância para o desenvolvimento de atividades inovativas (entre } \\
2009 \text { e 2011). }\end{array}$ \\
\hline Obsmerc & $\begin{array}{l}\text { Obstáculo } \\
\text { acesso } \\
\text { informação } \\
\text { mercado }\end{array}$ & $\begin{array}{l}\text { Variável Binária, que recebe valor unitário caso a firma aponte que } \\
\text { obstáculos referentes à falta de informação sobre mercados obtiveram alta } \\
\text { ou média importância para o desenvolvimento de atividades inovativas (entre } \\
2009 \text { e 2011). }\end{array}$ \\
\hline \multicolumn{3}{|c|}{ vii) Classificação Setorial } \\
\hline IntTecSetor & $\begin{array}{l}\text { Intensidade } \\
\text { Tecnológica } \\
\text { Setor }\end{array}$ & $\begin{array}{l}\text { Variável Contínua que indica a relação entre os gastos com atividades } \\
\text { inovativas e a receita líquida de vendas das empresas atuantes no setor de } \\
\text { acordo com CNAE a } 2 \text { dígitos. }\end{array}$ \\
\hline \multicolumn{3}{|c|}{ viii) Região Geográfica } \\
\hline Região & Região Geográfica & $\begin{array}{l}\text { Conjunto de } 5 \text { Variáveis Binárias de regiões geográficas, que recebem } \\
\text { valores unitários caso a firma esteja localizada em uma dessas cinco regiões } \\
\text { do Brasil (Norte, Nordeste, Sul, Sudeste e Centro-Oeste). }\end{array}$ \\
\hline
\end{tabular}




\subsection{Metodologia}

A estratégia empírica desse trabalho consiste na especificação e estimação de modelos probabilísticos para investigar a relação entre o esforço inovativo, medido pelos gastos com atividades inovativas, e probabilidade de a empresa cooperar para inovação (Cameron; Trivedi, 2010; Wooldridge, 2010). Vale ressaltar que, dada a disponibilidade de dados, o estudo se restringe a analisar a cooperação como uma variável binária (coopera x não coopera), não sendo possível desenvolver uma análise pormenorizada dessa relação de cooperação, como prazo de duração, conteúdo da relação de cooperação, abrindo-se, assim, espaço para agenda futura de pesquisa.

Considere a variável binária observável $y_{i}$ e a variável contínua não observável (latente) $y_{i}^{*}$, a qual satisfaz o seguinte modelo:

$y_{i}^{*}=\mathrm{x}_{i}^{\prime} \beta+u_{i}$

Onde $\mathrm{x}_{i}$ é um vetor coluna $k \times 1$ e $\beta$ é um vetor coluna $k \times 1$. Embora $y_{i}^{*}$ não seja observável, podese observar:

$y_{i}=\left\{\begin{array}{l}1, \text { se } y_{i}^{*}>0 \\ 0, \text { se } y_{i}^{*} \leq 0\end{array}\right.$

Dados os modelos (1) e (2) para a variável latente, tem-se:

$\operatorname{Pr}\left(y_{i}=1\right)=\operatorname{Pr}\left(\mathrm{x}_{i}^{\prime} \beta+u_{i}>0\right)$

$\operatorname{Pr}\left(y_{i}=1\right)=\operatorname{Pr}\left(-u_{i}<\mathrm{x}_{i}^{\prime} \beta\right)$

$\operatorname{Pr}\left(y_{i}=1\right)=F\left(\mathrm{x}_{i}^{\prime} \beta\right)$

Onde $F($.$) é uma função de distribuição cumulativa de -u_{i}$. Se $u_{i}$ é normalmente distribuído, tem-se o modelo probit.

Conforme Cassiman e Veugelers (2002), Faria e Schmidt (2007), Okamuro et al (2011) as variáveis de inovação são potencialmente endógenas no modelo probabilístico, o que torna necessário um procedimento de variáveis instrumentais.

No trabalho é utilizada uma variável de inovação contínua (lnGPD), utiliza-se o modelo IV Probit por ajustar modelos com variável binária e regressores endógenos contínuos.

A estrutura formal do modelo IV Probit é descrita por:

$y_{1 i}^{*}=y_{2 i} \beta+\mathrm{x}_{1 i}^{\prime} \gamma+u_{i}$

$y_{2 i}=\mathrm{x}_{1 i}^{\prime} \pi_{1}+\mathrm{x}_{2 i}^{\prime} \pi_{2}+v_{i}$

Onde $y_{2 i}$ é uma variável endógena, $\mathrm{x}_{1 i}$ é um vetor coluna $k_{1} \times 1$ de variáveis exógenas, $\mathrm{x}_{2 i}$ é um vetor coluna $k_{2} x 1$ de instrumentos adicionais, $\beta$ e $\gamma$ são vetores de parâmetros estruturais e $\pi_{1}$ e $\pi_{2}$ são vetores de parâmetros em forma reduzida. Embora $y_{1 i}^{*}$ não seja observável, pode-se observar:

$y_{1 i}=\left\{\begin{array}{l}1, \text { se } y_{1 i}^{*}>0 \\ 0, \text { se } y_{1 i}^{*} \leq 0\end{array}\right.$

Um teste Wald é utilizado para testar a hipótese nula de que a variável instrumentalizada é exógena.

Inicialmente, para investigar a relação entre o esforço inovativo e probabilidade de a empresa cooperar para inovação, foram especificados e estimados quinze modelos probabilísticos 
(probit), para os quais as variáveis binárias dependentes estão definidas no Quadro 1. Para cada um dos quinze modelos especificados, as variáveis explanatórias, conforme definidas no Quadro 2, são: PO; Grupo; Capest; lnGPD; Skill; Pdcont; Gov; Infconc; Infcad; Infpesq; Obsfinan; Obsorg; Obsqual; Obstec; Obsmerc; IntTecSetor; Região.

Em seguida foram especificados e estimados quinze modelos probabilísticos com uso de variável instrumental (IVprobit) para os quais as variáveis binárias dependentes estão definidas no Quadro 1. Para cada um dos quinze modelos especificados, as variáveis explanatórias, conforme definidas no Quadro 2, são: PO; Grupo; Capest; lnGPD; Skill; Pdcont; Gov; Infconc; Infcad; Infpesq; Obsfinan; Obsorg; Obsqual; Obstec; Obsmerc; IntTecSetor; Região. Como variável instrumental utilizou-se nessas estimações a intensidade tecnológica do setor (medida pela relação entre gastos com atividades inovativas e receita líquida de vendas de acordo com a CNAE a dois dígitos). Como afirma Okamuro et al (2011) acredita-se que a intensidade tecnológica do setor seja um instrumento adequado, pois está correlacionado com os gastos em $\mathrm{P} \& \mathrm{D}$, mas não com a decisão de cooperação para inovação. Vale ressaltar que testes de validade de instrumentos (teste de Sargan) só podem ser feitos quando se utiliza mais de um instrumento.

\section{Apresentação dos resultados}

As características das empresas da amostra estão apresentadas nas Tabelas 3 e 4 . As estatísticas descritivas estão divididas em variáveis contínuas e binárias. As variáveis contínuas são referentes ao ano de 2011, enquanto as variáveis binárias estão compreendidas entre os anos de 2009 e 2011. A amostra total é composta de empresas inovadoras, ou seja, que implementaram alguma inovação, seja ela de produto ou processo, no período entre 2009 e 2011 (PINTEC, 2013). As subamostras são representadas pelos tipos de cooperação também destacados no Quadro 1.

Tabela 1

Estatística Descritiva - Variáveis Contínuas - Médias

\begin{tabular}{|c|c|c|c|c|}
\hline & $\begin{array}{l}\text { Pessoal } \\
\text { Ocupado } \\
\text { (número) }\end{array}$ & $\begin{array}{c}\text { Gastos com } \\
\text { P\&D } \\
\text { (Milhares } \\
\text { Reais) }\end{array}$ & $\begin{array}{c}\text { Gastos com } \\
\text { Atividades } \\
\text { Inovativas* } \\
\text { (Milhares } \\
\text { Reais) } \\
\end{array}$ & Observ. \\
\hline Total & 383,3 & $1.312,1$ & $3.310,2$ & 11.159 \\
\hline Inovadoras & 521,0 & $2.737,1$ & $6.904,5$ & 5.298 \\
\hline Coop & 960,9 & $7.100,1$ & $13.537,21$ & 1.512 \\
\hline CoopCad & $1.008,5$ & $7.785,4$ & $14.247,2$ & 1.301 \\
\hline CoopConc & $1.146,4$ & $13.737,0$ & $18.586,8$ & 399 \\
\hline CoopGru & $1.998,0$ & $22.415,3$ & $38.876,7$ & 331 \\
\hline CoopPesp & $1.103,4$ & $8.611,4$ & $16.687,7$ & 1.020 \\
\hline CoopExt & $2.139,9$ & $26.164,6$ & $44.340,8$ & 202 \\
\hline CoopCadExt & $1.721,5$ & $13.116,0$ & $27.723,6$ & 132 \\
\hline CoopConcExt & $3.769,5$ & $106.613,8$ & $122.343,7$ & 32 \\
\hline CoopGruExt & $2.819,3$ & $9.159,1$ & $38.496,5$ & 50 \\
\hline CoopPespExt & $2.269,0$ & $15.219,3$ & $29.409,4$ & 43 \\
\hline CoopBra & $1.530,1$ & $18.865,5$ & $31.525,8$ & 413 \\
\hline CoopCadBra & $1.593,1$ & $21.252,4$ & $33.674,8$ & 305 \\
\hline CoopConcBra & $1.946,8$ & $12.577,8$ & $22.606,2$ & 74 \\
\hline CoopGruBra & $5.571,9$ & $167.885,9$ & $216.390,6$ & 19 \\
\hline CoopPespBra & $1.846,5$ & $29.656,3$ & $43.504,0$ & 193 \\
\hline
\end{tabular}

Fonte: Elaboração dos autores a partir de PINTEC (2013). 
Pela Tabela 1 pode-se verificar que das 5.298 empresas inovadoras, 1.512 realizaram, entre 2009 e 2011, alguma atividade de cooperação para inovação. Dentre os tipos de parceiros, a cooperação com cadeia produtiva (clientes e fornecedores) concentram o maior número de empresas que cooperam (1.301 empresas) e a cooperação com grupo, por sua vez, apresenta o menor número de empresas (331 empresas). Quanto às empresas que cooperam no exterior observa-se que o número de empresas é pequeno, somente 202 empresas cooperam com instituições no exterior, sendo que 132 delas realizaram cooperação com empresas da cadeia produtiva (clientes e fornecedores) e 50 cooperaram com empresas do grupo sediadas no exterior.

Quanto ao tamanho médio das empresas analisadas verifica-se que enquanto as empresas inovadoras possuem em média 521 pessoas ocupadas, as que cooperam possuem 960,9 pessoas ocupadas, em média. Dentre os tipos de parceiros, as empresas com maior tamanho em média são as que cooperam com o grupo; das que cooperam no exterior, as que possuem maior número de pessoas ocupadas são as que cooperam com concorrentes sediados no exterior (3769,5 pessoas ocupadas, em média); e das que cooperam no Brasil, as que possuem maior número de pessoas ocupadas são as que cooperam com empresas do grupo (5.571,9 pessoas ocupadas, em média).

Ainda na Tabela 1 pode-se destacar a grande diferença entre os gastos com P\&D e com atividades inovativas das empresas que cooperam em relação às que não cooperam. Percebe-se que o valor gasto com $P \& D$ das empresas que cooperam é de, em média, $R \$ 7,1$ milhões, enquanto o mesmo gasto para as inovadoras que não cooperam é de, em média, de $\mathrm{R} \$ 2,7$ milhões. $\mathrm{O}$ gasto com $P \& D$ destaca-se ainda mais no caso de empresas que cooperam com o exterior cujo montante alcança, em média, R \$ 26,1 milhões, e de empresas que cooperam no Brasil com o valor, em média, de R \$18,8 milhões. Ao se considerar o tipo de parceiro, as empresas que cooperam no Brasil que mais gastam em P\&D são as que cooperam com empresas do mesmo grupo (média de $\mathrm{R} \$ 167,8$ milhões) e dentre as que cooperam no exterior as que mais gastam em P\&D são as empresas que cooperam com seus concorrentes (média de $\mathrm{R} \$ 106,6$ milhões).

As estatísticas descritivas das variáveis binárias estão reportadas na Tabela 2 a seguir. Ao se observar a maioria dos indicadores verifica-se que os percentuais são geralmente maiores quando a empresa coopera em relação às que não cooperam e ainda maior quando a empresa coopera com instituições no exterior, em relação às que cooperam apenas com empresas no Brasil. 
Tabela 2

Estatística descritiva - Variáveis binárias (\%)

\begin{tabular}{|c|c|c|c|c|c|c|c|c|c|c|c|c|c|c|c|c|c|c|c|}
\hline & \multirow{2}{*}{$\begin{array}{l}\text { Capital } \\
\text { Estrang. }\end{array}$} & \multirow[b]{2}{*}{ Grupo } & \multirow[b]{2}{*}{ Skill } & \multirow{2}{*}{$\begin{array}{c}\text { P\&D } \\
\text { Contínuo }\end{array}$} & \multirow{2}{*}{$\begin{array}{c}\text { Apoio } \\
\text { do } \\
\text { Governo }\end{array}$} & \multicolumn{3}{|c|}{ Fontes de Informação } & \multicolumn{6}{|c|}{ Região Geográfica } & \multicolumn{4}{|c|}{ Obstáculos } & \multirow{2}{*}{ Obs. } \\
\hline & & & & & & Cadeia & Conc & Pesq & Norte & Nordeste & $\begin{array}{l}\text { Centro } \\
\text {-Oeste }\end{array}$ & Sul & Sudeste & Finan & Org & Qual & Tec & Mercad & \\
\hline Total & 10,3 & 14,7 & 15,7 & 16,7 & 20,1 & 49,5 & 26,4 & 26,8 & 3,9 & 9,5 & 4,3 & 29,9 & 52,3 & 19,6 & 13,6 & 21 & 13,8 & 12,6 & 11.159 \\
\hline Inovadoras & 13,5 & 17,7 & 31,6 & 33,4 & 40,2 & 96,1 & 51,5 & 52,5 & 3,3 & 8,9 & 4,4 & 32,2 & 51,2 & 26,1 & 19,1 & 30,4 & 20,6 & 18,5 & 5.298 \\
\hline Coop & 20,2 & 27,6 & 49,5 & 52,3 & 50,7 & 98,9 & 54,3 & 69 & 3,7 & 7,7 & 4,7 & 32 & 51,9 & 30,4 & 22,2 & 34,9 & 23,1 & 22 & 1.512 \\
\hline CoopCad & 19 & 26,1 & 49,6 & 52,7 & 51,3 & 99,7 & 57 & 70,4 & 3,3 & 7,8 & 4,3 & 32,9 & 51,7 & 30,7 & 22,8 & 34,9 & 23,7 & 22,7 & 1.301 \\
\hline CoopConc & 14,3 & 22,3 & 51,9 & 52,9 & 53,1 & 99,5 & 92,2 & 79,2 & 4 & 10 & 5,5 & 30,8 & 49,6 & 32,1 & 26,1 & 34,8 & 25,1 & 22,3 & 399 \\
\hline CoopGru & 66,5 & 69,8 & 65 & 68,3 & 57,4 & 99,7 & 56,2 & 72,5 & 4,5 & 6,3 & 3,3 & 20,2 & 65,6 & 20,8 & 21,5 & 28,4 & 19 & 15,1 & 331 \\
\hline CoopPesp & 18,2 & 27,8 & 53,3 & 57,9 & 55,7 & 99,2 & 58,5 & 87,3 & 3,6 & 8,6 & 5,7 & 30,7 & 51,4 & 32,9 & 24,3 & 37,5 & 24,8 & 23,9 & 1.020 \\
\hline CoopExt & 41,6 & 39,1 & 72,3 & 74,8 & 68,8 & 99,5 & 53,5 & 83,7 & 3,5 & 7,4 & 1 & 19,3 & 68,8 & 30,7 & 23,8 & 35,6 & 21,8 & 26,2 & 202 \\
\hline CoopCadExt & 33,3 & 32,6 & 69,7 & 72,7 & 68,2 & 99,2 & 49,2 & 85,6 & 4,5 & 6,8 & 0,8 & 24,2 & 63,6 & 28 & 18,9 & 37,9 & 25 & 28,8 & 132 \\
\hline CoopConcExt & 21,9 & 40,6 & 71,9 & 75 & 78,1 & 100 & 81,3 & 96,9 & 6,3 & 6,3 & 0 & 9,4 & 78,1 & 31,3 & 37,5 & 50 & 15,6 & 28,1 & 32 \\
\hline CoopGruExt & 90 & 60 & 80 & 76 & 72 & 100 & 48 & 78 & 2 & 6 & 0 & 12 & 80 & 20 & 34 & 20 & 14 & 18 & 50 \\
\hline CoopPespExt & 25,6 & 32,6 & 74,4 & 83,7 & 72,1 & 100 & 55,8 & 93 & 4,7 & 14 & 2,3 & 9,3 & 69,8 & 48,8 & 23,3 & 51,2 & 37,2 & 46,5 & 43 \\
\hline CoopBra & 25,2 & 31,5 & 62,2 & 65,4 & 59,1 & 99,5 & 60,3 & 78 & 3,9 & 8 & 3,1 & 27,1 & 57,9 & 31,2 & 18,9 & 32,9 & 22,3 & 22,5 & 413 \\
\hline CoopCadBra & 24,6 & 32,8 & 61 & 64,9 & 57,4 & 99,3 & 58 & 73,8 & 3,9 & 7,2 & 3 & 26,6 & 59,3 & 33,8 & 20,7 & 34,8 & 23,9 & 25,2 & 305 \\
\hline CoopConcBra & 20,3 & 31,1 & 67,6 & 68,9 & 51,4 & 100 & 77 & 85,1 & 4,1 & 2,7 & 2,7 & 29,7 & 60,8 & 36,5 & 27 & 36,5 & 24,3 & 23 & 74 \\
\hline CoopGruBra & 57,9 & 89,5 & 94,7 & 100 & 84,2 & 100 & 73,7 & 89,5 & 5,3 & 21,1 & 0 & 10,5 & 63,2 & 21,1 & 10,5 & 36,8 & 15,8 & 10,5 & 19 \\
\hline CoopPespBra & 27,5 & 34,2 & 71,5 & 72,5 & 70,5 & 100 & 67,9 & 87,6 & 3,6 & 6,7 & 2,1 & 28,5 & 59,1 & 30,6 & 19,2 & 34,7 & 22,3 & 22,3 & 193 \\
\hline
\end{tabular}

Fonte: Elaboração própria a partir de PINTEC (2013). 
Quanto às características das empresas observa-se que as empresas que cooperam possuem maior participação de capital estrangeiro, com destaque para as empresas que cooperam no exterior. Esse resultado coincide com evidências encontradas nos estudos internacionais, uma vez que se acredita que as empresas com capital estrangeiro estão mais abertas ao conhecimento externo do que as empresas de capital estritamente nacional. De maneira análoga, as empresas que cooperam participam mais de grupos em relação às empresas inovadoras que não cooperam.

Quanto aos indicadores de capacitação tecnológica, espera-se que as empresas que cooperam possuam esses indicadores superiores em relação às empresas que não cooperam. Os resultados apontam que, quanto à variável skill, as empresas que cooperam possuem um maior percentual de pessoal ocupado com $3^{\circ}$ grau $(49,5 \%)$ enquanto as inovadoras possuem somente $31,6 \%$ do total do pessoal ocupado com $3^{\circ}$ grau. Dentre os tipos de parceiros, as empresas que cooperam com empresas do grupo possuem um percentual mais elevado, de $65 \%$ de pessoal ocupado com $3^{\circ}$ grau. No caso das empresas que cooperam com o exterior, esse percentual se eleva em todos os casos, sendo as empresas que cooperam com grupo no exterior as que possuem um percentual de $80 \%$ do pessoal ocupado com $3^{\circ}$ grau. No caso das empresas que cooperam no país, $62,2 \%$ do pessoal ocupado é de $3^{\circ}$ grau, sendo as que cooperam com grupo com o maior percentual $(94,7 \%)$. No que tange à variável $\mathrm{P} \& \mathrm{D}$ contínuo, observa-se que os indicadores das empresas que cooperam também são superiores aos das empresas inovadoras (52,3\% versus $33,4 \%)$. Quanto ao tipo de parceiro, destacam-se as empresas que cooperam com o grupo sendo que $68,3 \%$ delas realizam P\&D contínuo. No caso das empresas que cooperam no exterior, destacam-se as empresas que cooperam com instituições de pesquisa $(83,7 \%$ realizam P\&D contínuo), enquanto que no caso das empresas que cooperam no Brasil, são as empresas que cooperam com grupo que realizam na sua totalidade atividades de P\&D contínuo.

Dentre as empresas que cooperam e recebem apoio do governo, verifica-se que o grupo de empresas cujo percentual é mais elevado é o de empresas que cooperam com grupo, com mais de $57 \%$ das empresas beneficiadas por algum programa de apoio à inovação. No caso das empresas que cooperam no exterior, são as empresas que cooperam com concorrentes que possuem maior participação em programas de apoio públicos $(78,1 \%)$, enquanto que no caso das empresas que cooperam no Brasil, são as que cooperam com grupo que apresentam maior participação $(84,2 \%)$. Quanto às fontes de informação, a maioria das empresas considera como uma importante fonte de informação a cadeia produtiva (clientes e fornecedores) para a realização da inovação, alcançando $100 \%$ das empresas em alguns casos. No que tange à distribuição geográfica nota-se uma importante concentração nas empresas que inovam e cooperam, independente do parceiro, nas regiões Sul e Sudeste do país.

A Tabela 3, sistematiza os resultados dos quinze modelos probit estimados. Ao se avaliar os resultados do modelo com a amostra completa, independente do parceiro e da localização (coluna 1), verifica-se que os gastos com $\mathrm{P} \& \mathrm{D}$ possui coeficiente associado positivo $\mathrm{e}$ estatisticamente significativo, indicando que o esforço interno com $P \& D$ aumenta a probabilidade de as empresas realizarem atividades de cooperação para inovação. Dentre as características das empresas observa-se que o aumento do tamanho, a participação em um grupo e o apoio do governo aumentam a probabilidade de a empresa cooperar. Negassi (2004), Badillo, Galera e Serrano (2017) e de Moraes et al. (2018) também encontram evidências sobre o tamanho da empresa e o importante papel do apoio do governo na decisão da empresa de cooperar para inovar. Dentre as variáveis de fontes de informação, apenas a variável que representa a alta importância dada às informações obtidas em instituições de pesquisa e Universidades possui coeficiente 
associado positiva e estatisticamente significativo. Dentre as variáveis de obstáculo à inovação, as empresas que consideram a falta de fontes de financiamento um obstáculo à inovação tem maior probabilidade de cooperar.

As colunas (2), (3), (4) e (5) da Tabela 3 apresentam os resultados dos modelos com as amostras desagregadas por tipo de parceiro, sendo cadeia produtiva, concorrentes, grupo e instituições de pesquisa, respectivamente. Pelos resultados apresentados na coluna (2), gastos com $\mathrm{P} \& \mathrm{D}$, receber apoio do governo, participar de grupo, obter informações de instituições de pesquisa e considerar as fontes de financiamento um obstáculo à inovação aumentam a probabilidade de cooperar.

Na coluna (3) da Tabela 3 estão os resultados do modelo com empresas que realizam cooperação com concorrentes. Os resultados encontrados apontam que somente as empresas que consideram de alta importância a obtenção de fontes de informação dos concorrentes e de instituições de pesquisa aumentam a probabilidade de cooperar. Na coluna (4) da Tabela 3 estão os resultados do modelo com empresas que realizam cooperação com grupo. Os resultados encontrados apontam possuir capital estrangeiro, participar de grupo, obter informações de concorrentes e de instituições de pesquisa aumentam a probabilidade de cooperar. A coluna (5) da Tabela 3 organiza os resultados do modelo com empresas que cooperam com instituições de pesquisa. Pelos resultados apresentados, gastos com $\mathrm{P} \& \mathrm{D}$, aumento do tamanho da empresa, participação de grupo, apoio do governo, obtenção de informações de instituições de pesquisa e considerar a falta de financiamento um obstáculo à inovação aumentam a probabilidade de cooperar. Faria et al (2010) encontram resultados semelhantes quanto ao fato de fazer parte de grupo e dos gastos em $\mathrm{P} \& \mathrm{D}$ gerarem impacto positivo sobre a probabilidade de as empresas cooperarem.

As colunas de (6) a (10) da Tabela 3 apresentam os resultados do modelo agregado e dos quatro modelos desagregados por tipo de parceiro considerando apenas as empresas que cooperaram com agentes no exterior. Os resultados apresentados para todas as empresas que cooperam no exterior (coluna 6) sugerem que o indicador de qualificação tecnológica (skill) possui coeficiente associado positivo e estatisticamente significativo, indicando que maior percentual de pessoal ocupado com $3^{\circ}$ grau aumenta a probabilidade de as empresas realizarem atividades de cooperação para inovação com o exterior, assim como os resultados evidenciados por Faria et al (2010) e Okamuro et al (2011). O aumento do tamanho da empresa, possuir capital estrangeiro, receber apoio do governo e considerar como de alta importância as informações obtidas em instituições de pesquisa aumenta a probabilidade de cooperar.

Os resultados da coluna (7) a (10) da Tabela 3 apresentam os resultados dos modelos com as amostras desagregadas por tipo de parceiro, sendo cadeia produtiva, concorrentes, grupo e instituições de pesquisa, respectivamente. Pelos resultados apresentados na coluna (7), tamanho da empresa, apoio do governo e obter informações de instituições de pesquisa aumentam a probabilidade de cooperar com outras empresas no exterior. Na coluna (8) da Tabela 3 estão os resultados do modelo com empresas que realizam cooperação com concorrentes no exterior. Os resultados apontam que o indicador de apoio do governo e considerar de alta importância os concorrentes e as instituições de pesquisa como fontes de informação aumenta a probabilidade de cooperar para inovar.

Quanto aos resultados do modelo com empresas que cooperam com grupo no exterior (coluna 9), verifica-se que tamanho da empresa, ter capital estrangeiro, ter apoio do governo e 
obter informações de instituições de pesquisa aumentam a probabilidade de cooperar. Pelos resultados apresentados na coluna (10) da Tabela 3, aumento do tamanho da empresa, obtenção de informações de instituições de pesquisa e considerar a falta de qualificação de mão-de-obra um obstáculo à inovação possuem coeficientes associados positivos e estatisticamente significativos, indicando que essas variáveis aumentam a probabilidade de as empresas realizarem cooperação para inovação com instituições de pesquisa no exterior.

As colunas de (11) a (15) da Tabela 3 apresentam os resultados do modelo agregado e dos quatro modelos desagregados por tipo de parceiro considerando apenas as empresas que cooperaram com agentes no país. Os resultados apresentados para todas as empresas que cooperam no Brasil (coluna 11) sugerem que os gastos com P\&D possuem coeficiente associado positivo e estatisticamente significativo, indicando que o esforço de $P \& D$ aumenta a probabilidade de as empresas realizarem atividades de cooperação para inovação com o exterior. $\mathrm{O}$ aumento do tamanho da empresa, possuir pessoal ocupado com $3^{\circ}$ grau e considerar como de alta importância as informações obtidas em instituições de pesquisa aumenta a probabilidade de cooperar. 
Tabela 3

Modelos Probit

\begin{tabular}{|c|c|c|c|c|c|c|c|c|c|c|c|c|c|c|c|}
\hline & \multicolumn{5}{|c|}{ Cooperação } & \multicolumn{5}{|c|}{ Cooperação no Exterior } & \multicolumn{5}{|c|}{ Cooperação no Brasil } \\
\hline & $\begin{array}{l}\text { Coop } \\
(1)\end{array}$ & $\begin{array}{c}\text { CoopCad } \\
(2)\end{array}$ & $\begin{array}{l}\text { CoopConc } \\
\text { (3) }\end{array}$ & $\begin{array}{c}\text { CoopGru } \\
(4)\end{array}$ & $\begin{array}{c}\text { CoopPesq } \\
\text { (5) }\end{array}$ & $\begin{array}{c}\text { CoopExt } \\
(6)\end{array}$ & $\begin{array}{c}\text { CoopCadExt } \\
(7)\end{array}$ & $\begin{array}{c}\text { CoopConcExt } \\
(8)\end{array}$ & $\begin{array}{c}\text { CoopGruExt } \\
(9)\end{array}$ & $\begin{array}{c}\text { CoopPesqExt } \\
(10)\end{array}$ & $\begin{array}{c}\text { CoopBra } \\
(11)\end{array}$ & $\begin{array}{c}\text { CoopCadBra } \\
\text { (12) }\end{array}$ & $\begin{array}{c}\text { CoopConcBra } \\
\text { (13) }\end{array}$ & $\begin{array}{c}\text { CoopGruBra } \\
\text { (14) }\end{array}$ & $\begin{array}{c}\text { CoopPesqBra } \\
(15)\end{array}$ \\
\hline $\operatorname{lnGDP}$ & $\begin{array}{c}0,056^{* * * *} \\
(0,021)\end{array}$ & $\begin{array}{c}0,064 * * * \\
(0,021)\end{array}$ & $\begin{array}{c}0,040 \\
(0,031)\end{array}$ & $\begin{array}{l}0,050 \\
(0,034)\end{array}$ & $\begin{array}{c}0,086 * * * \\
(0,023)\end{array}$ & $\begin{array}{c}0,015 \\
(0,032)\end{array}$ & $\begin{array}{c}0,017 \\
(0,036)\end{array}$ & $\begin{array}{c}0,064 \\
(0,065)\end{array}$ & $\begin{array}{l}-0,081 \\
(0,061)\end{array}$ & $\begin{array}{l}-0,027 \\
(0,062)\end{array}$ & $\begin{array}{c}0,077 \text { *** } \\
(0,028)\end{array}$ & $\begin{array}{c}0,102 * * * \\
(0,031)\end{array}$ & $\begin{array}{c}0,094 * * \\
(0,045)\end{array}$ & $\begin{array}{c}0,139 \\
(0,088)\end{array}$ & $\begin{array}{c}0,095 \text { **** } \\
(0,036)\end{array}$ \\
\hline $\ln \mathrm{PO}$ & $\begin{array}{l}0,054^{*} \\
(0,029)\end{array}$ & $\begin{array}{c}0,048 \\
(0,029)\end{array}$ & $\begin{array}{c}0,053 \\
(0,039)\end{array}$ & $\begin{array}{l}-0,003 \\
(0,043)\end{array}$ & $\begin{array}{c}0,063 \text { ** } \\
(0,031)\end{array}$ & $\begin{array}{c}0,179 * * * \\
(0,047)\end{array}$ & $\begin{array}{c}0,145 * * * * \\
(0,055)\end{array}$ & $\begin{array}{c}0,100 \\
(0,091)\end{array}$ & $\begin{array}{c}0,239^{* * * *} \\
(0,087)\end{array}$ & $\begin{array}{c}0,340^{* * * * *} \\
(0,092)\end{array}$ & $\begin{array}{c}0,145^{* * * *} \\
(0,038)\end{array}$ & $\begin{array}{c}0,138^{* * * *} \\
(0,041)\end{array}$ & $\begin{array}{c}0,226^{* * * *} \\
(0,066)\end{array}$ & $\begin{array}{c}0,063 \\
(0,104)\end{array}$ & $\begin{array}{c}0,118^{* * *} \\
(0,046)\end{array}$ \\
\hline Skill & $\begin{array}{c}0,040 \\
(0,125)\end{array}$ & $\begin{array}{c}0,104 \\
(0,128)\end{array}$ & $\begin{array}{c}0,148 \\
(0,172)\end{array}$ & $\begin{array}{c}0,213 \\
(0,244)\end{array}$ & $\begin{array}{l}-0,137 \\
(0,142)\end{array}$ & $\begin{array}{l}0,531^{*} \\
(0,289)\end{array}$ & $\begin{array}{c}0,464 \\
(0,333)\end{array}$ & - & $\begin{array}{c}0,381 \\
(0,445)\end{array}$ & - & $\begin{array}{c}0,616^{* * * *} \\
(0,201)\end{array}$ & $\begin{array}{c}0,659 * * * \\
(0,244)\end{array}$ & - & - & $\begin{array}{c}0,587^{* * *} \\
(0,234)\end{array}$ \\
\hline Capest & $\begin{array}{c}0,091 \\
(0,083)\end{array}$ & $\begin{array}{c}0,022 \\
(0,085)\end{array}$ & $\begin{array}{l}-0,154 \\
(0,119)\end{array}$ & $\begin{array}{c}1,287 * * * \\
(0,112)\end{array}$ & $\begin{array}{l}-0,113 \\
(0,094)\end{array}$ & $\begin{array}{c}0,425 * * * * \\
(0,122)\end{array}$ & $\begin{array}{c}0,232 \\
(0,147)\end{array}$ & $\begin{array}{l}-0,480 \\
(0,321)\end{array}$ & $\begin{array}{c}1,696 * * * \\
(0,245)\end{array}$ & $\begin{array}{l}-0,031 \\
(0,251)\end{array}$ & $\begin{array}{c}0,103 \\
(0,103)\end{array}$ & $\begin{array}{l}-0,005 \\
(0,113)\end{array}$ & $\begin{array}{l}-0,234 \\
(0,167)\end{array}$ & $\begin{array}{c}1,001 * * * \\
(0,352)\end{array}$ & $\begin{array}{c}0,082 \\
(0,122)\end{array}$ \\
\hline Gov & $\begin{array}{c}0,186^{* * * *} \\
(0,066)\end{array}$ & $\begin{array}{l}0,161 * * \\
(0,066)\end{array}$ & $\begin{array}{c}0,127 \\
(0,092)\end{array}$ & $\begin{array}{c}0,097 \\
(0,104)\end{array}$ & $\begin{array}{c}0,250 * * * \\
(0,073)\end{array}$ & $\begin{array}{c}0,314 * * * * \\
(0,103)\end{array}$ & $\begin{array}{r}0,237^{* * *} \\
(0,116)\end{array}$ & $\begin{array}{l}0,456^{*} \\
(0,253)\end{array}$ & $\begin{array}{c}0,506^{* *} \\
(0,235)\end{array}$ & $\begin{array}{c}0,097 \\
(0,177)\end{array}$ & $\begin{array}{c}0,119 \\
(0,083)\end{array}$ & $\begin{array}{c}0,047 \\
(0,088)\end{array}$ & $\begin{array}{l}-0,225 \\
(0,146)\end{array}$ & $\begin{array}{c}0,428 \\
(0,261)\end{array}$ & $\begin{array}{r}0,241^{* *} \\
(0,103)\end{array}$ \\
\hline Pdcont & $\begin{array}{l}-0,015 \\
(0,096)\end{array}$ & $\begin{array}{l}-0,063 \\
(0,098)\end{array}$ & $\begin{array}{l}-0,094 \\
(0,135)\end{array}$ & $\begin{array}{c}0,109 \\
(0,175)\end{array}$ & $\begin{array}{c}0,017 \\
(0,111)\end{array}$ & $\begin{array}{c}0,097 \\
(0,176)\end{array}$ & $\begin{array}{c}0,145 \\
(0,203)\end{array}$ & - & $\begin{array}{l}-0,125 \\
(0,328)\end{array}$ & $\begin{array}{l}-0,008 \\
(0,334)\end{array}$ & $\begin{array}{l}-0,083 \\
(0,128)\end{array}$ & $\begin{array}{l}-0,158 \\
(0,141)\end{array}$ & $\begin{array}{l}-0,266 \\
(0,226)\end{array}$ & - & $\begin{array}{l}-0,290^{*} \\
(0,153)\end{array}$ \\
\hline Grupo & $\begin{array}{c}0,342 * * * \\
(0,075)\end{array}$ & $\begin{array}{c}0,230^{* * * *} \\
(0,076)\end{array}$ & $\begin{array}{l}-0,018 \\
(0,102)\end{array}$ & $\begin{array}{c}1,089^{* * * *} \\
(0,099)\end{array}$ & $\begin{array}{c}0,286^{* * * *} \\
(0,082)\end{array}$ & $\begin{array}{c}0,094 \\
(0,112)\end{array}$ & $\begin{array}{l}-0,016 \\
(0,136)\end{array}$ & $\begin{array}{l}-0,018 \\
(0,221)\end{array}$ & $\begin{array}{c}0,229 \\
(0,170)\end{array}$ & $\begin{array}{l}-0,144 \\
(0,197)\end{array}$ & $\begin{array}{c}0,046 \\
(0,092)\end{array}$ & $\begin{array}{c}0,081 \\
(0,098)\end{array}$ & $\begin{array}{c}0,075 \\
(0,154)\end{array}$ & $\begin{array}{c}1,134 * * * \\
(0,346)\end{array}$ & $\begin{array}{c}0,060 \\
(0,111)\end{array}$ \\
\hline Fcadeia & $\begin{array}{c}0,375 \\
(0,355)\end{array}$ & - & $\begin{array}{l}-0,119 \\
(0,454)\end{array}$ & - & $\begin{array}{c}0,374 \\
(0,469)\end{array}$ & - & - & - & - & - & - & - & - & - & - \\
\hline Fconc & $\begin{array}{l}-0,044 \\
(0,063)\end{array}$ & $\begin{array}{c}0,085 \\
(0,064)\end{array}$ & $\begin{array}{c}1,221 * * * \\
(0,114)\end{array}$ & $\begin{array}{l}0,177^{*} \\
(0,102)\end{array}$ & $\begin{array}{l}-0,034 \\
(0,070)\end{array}$ & $\begin{array}{l}-0,101 \\
(0,097)\end{array}$ & $\begin{array}{c}-0,250 * * \\
(0,108)\end{array}$ & $\begin{array}{c}0,533^{* * *} \\
(0,242)\end{array}$ & $\begin{array}{l}-0,220 \\
(0,171)\end{array}$ & $\begin{array}{c}0,043 \\
(0,171)\end{array}$ & $\begin{array}{c}0,102 \\
(0,081)\end{array}$ & $\begin{array}{c}0,104 \\
(0,088)\end{array}$ & $\begin{array}{l}0,272^{*} \\
(0,145)\end{array}$ & $\begin{array}{c}0,227 \\
(0,287)\end{array}$ & $\begin{array}{c}0,153 \\
(0,097)\end{array}$ \\
\hline Fpesq & $\begin{array}{c}0,471 * * * \\
(0,068)\end{array}$ & $\begin{array}{c}0,438 * * * \\
(0,069)\end{array}$ & $\begin{array}{c}0,374 * * * \\
(0,101)\end{array}$ & $\begin{array}{c}0,534 * * * \\
(0,117)\end{array}$ & $\begin{array}{c}1,166 * * * \\
(0,083)\end{array}$ & $\begin{array}{c}0,562 * * * \\
(0,120)\end{array}$ & $\begin{array}{c}0,658 * * * \\
(0,136)\end{array}$ & $\begin{array}{c}0,600^{* *} \\
(0,306)\end{array}$ & $\begin{array}{c}0,429^{* *} \\
(0,216)\end{array}$ & $\begin{array}{c}0,899 * * * \\
(0,294)\end{array}$ & $\begin{array}{c}0,515 * * * \\
(0,095)\end{array}$ & $\begin{array}{c}0,357 * * * \\
(0,103)\end{array}$ & $\begin{array}{c}0,494 * * * \\
(0,182)\end{array}$ & $\begin{array}{c}0,530^{* *} \\
(0,267)\end{array}$ & $\begin{array}{c}0,564 * * * \\
(0,122)\end{array}$ \\
\hline Obsfinan & $\begin{array}{c}0,215^{* * * *} \\
(0,083)\end{array}$ & $\begin{array}{c}0,189 * * \\
(0,085)\end{array}$ & $\begin{array}{c}0,103 \\
(0,112)\end{array}$ & $\begin{array}{l}-0,037 \\
(0,131)\end{array}$ & $\begin{array}{c}0,220 * * \\
(0,089)\end{array}$ & $\begin{array}{c}0,284 * * \\
(0,126)\end{array}$ & $\begin{array}{c}0,120 \\
(0,1470\end{array}$ & $\begin{array}{c}0,015 \\
(0,224)\end{array}$ & $\begin{array}{c}0,384 \\
(0,263)\end{array}$ & $\begin{array}{c}0,309 \\
(0,208)\end{array}$ & $\begin{array}{c}0,303 * * * \\
(0,099)\end{array}$ & $\begin{array}{c}0,325^{* * *} \\
(0,107)\end{array}$ & $\begin{array}{c}0,372 * * \\
(0,164)\end{array}$ & $\begin{array}{c}0,303 \\
(0,314)\end{array}$ & $\begin{array}{l}0,218^{*} \\
(0,115)\end{array}$ \\
\hline Obsorg & $\begin{array}{c}-0,034 \\
(0,095)\end{array}$ & $\begin{array}{c}0,017 \\
(0,096)\end{array}$ & $\begin{array}{c}0,173 \\
(0,116)\end{array}$ & $\begin{array}{l}-0,029 \\
(0,152)\end{array}$ & $\begin{array}{l}-0,026 \\
(0,104)\end{array}$ & $\begin{array}{l}-0,153 \\
(0,144)\end{array}$ & $\begin{array}{c}-0,369 * * \\
(0,172)\end{array}$ & $\begin{array}{c}0,426 * * \\
(0,215)\end{array}$ & $\begin{array}{c}0,307 \\
(0,260)\end{array}$ & $\begin{array}{l}-0,476^{*} \\
(0,281)\end{array}$ & $\begin{array}{l}-0,204 \\
(0,125)\end{array}$ & $\begin{array}{l}-0,096 \\
(0,133)\end{array}$ & $\begin{array}{l}-0,176 \\
(0,206)\end{array}$ & $\begin{array}{l}-0,044 \\
(0,516)\end{array}$ & $\begin{array}{l}-0,185 \\
(0,147)\end{array}$ \\
\hline Obsqual & $\begin{array}{c}0,048 \\
(0,091)\end{array}$ & $\begin{array}{c}0,010 \\
(0,092)\end{array}$ & $\begin{array}{l}-0,038 \\
(0,123)\end{array}$ & $\begin{array}{c}0,036 \\
(0,145)\end{array}$ & $\begin{array}{c}0,020 \\
(0,096)\end{array}$ & $\begin{array}{c}0,090 \\
(0,141)\end{array}$ & $\begin{array}{c}0,155 \\
(0,170)\end{array}$ & $\begin{array}{l}0,336^{*} \\
(0,204)\end{array}$ & $\begin{array}{l}-0,465^{*} \\
(0,276)\end{array}$ & $\begin{array}{l}0,380^{*} \\
(0,204)\end{array}$ & $\begin{array}{c}0,094 \\
(0,115)\end{array}$ & $\begin{array}{c}0,065 \\
(0,123)\end{array}$ & $\begin{array}{c}0,031 \\
(0,174)\end{array}$ & $\begin{array}{c}0,150 \\
(0,257)\end{array}$ & $\begin{array}{c}0,174 \\
(0,128)\end{array}$ \\
\hline Obstec & $\begin{array}{l}-0,027 \\
(0,106)\end{array}$ & $\begin{array}{c}0,027 \\
(0,108)\end{array}$ & $\begin{array}{c}0,045 \\
(0,148)\end{array}$ & $\begin{array}{c}0,195 \\
(0,164)\end{array}$ & $\begin{array}{c}0,082 \\
(0,113)\end{array}$ & $\begin{array}{l}-0,088 \\
(0,168)\end{array}$ & $\begin{array}{c}0,094 \\
(0,192)\end{array}$ & $\begin{array}{c}-0,805^{* * *} * \\
(0,265)\end{array}$ & $\begin{array}{l}-0,126 \\
(0,382)\end{array}$ & $\begin{array}{l}-0,240 \\
(0,270)\end{array}$ & $\begin{array}{c}0,054 \\
(0,135)\end{array}$ & $\begin{array}{c}0,006 \\
(0,146)\end{array}$ & $\begin{array}{c}0,315 \\
(0,198)\end{array}$ & $\begin{array}{c}0,263 \\
(0,421)\end{array}$ & $\begin{array}{c}0,113 \\
(0,146)\end{array}$ \\
\hline Obsmerc & $\begin{array}{c}0,098 \\
(0,102)\end{array}$ & $\begin{array}{c}0,075 \\
(0,104)\end{array}$ & $\begin{array}{l}-0,032 \\
(0,135)\end{array}$ & $\begin{array}{l}-0,172 \\
(0,160)\end{array}$ & $\begin{array}{c}0,126 \\
(0,111)\end{array}$ & $\begin{array}{c}0,205 \\
(0,153)\end{array}$ & $\begin{array}{c}0,189 \\
(0,179)\end{array}$ & $\begin{array}{l}0,400^{*} \\
(0,205)\end{array}$ & $\begin{array}{c}0,302 \\
(0,329)\end{array}$ & $\begin{array}{l}0,490^{*} \\
(0,255)\end{array}$ & $\begin{array}{l}-0,011 \\
(0,132)\end{array}$ & $\begin{array}{c}0,049 \\
(0,139)\end{array}$ & $\begin{array}{l}-0,377 \\
(0,201)\end{array}$ & $\begin{array}{l}-0,429 \\
(0,392)\end{array}$ & $\begin{array}{l}-0,082 \\
(0,148)\end{array}$ \\
\hline Pseudo R2 & 0,086 & 0,077 & 0,18 & 0,35 & 0,192 & 0,189 & 0,166 & 0,273 & 0,387 & 0,256 & 0,135 & 0,129 & 0,167 & 0,399 & 0,142 \\
\hline Log-Likel. & $-1144,9$ & $-1109,5$ & $-557,6$ & $-431,2$ & $-926,4$ & $-416,8$ & $-306,1$ & $-81,4$ & $-114,9$ & $-114,2$ & $-647,2$ & $-525,4$ & $-181,5$ & $-53,03$ & $-425,6$ \\
\hline $\mathrm{N}^{\circ}$ Obs. & 1827 & 1808 & 1816 & 1801 & 1820 & 1802 & 1772 & 1119 & 1488 & 1456 & 1791 & 1772 & 1465 & 904 & 1791 \\
\hline
\end{tabular}

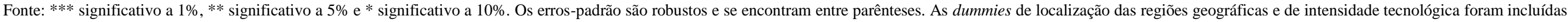
e não estão reportadas, bem como a constante. Para essas variáveis de regiões geográficas e de intensidade tecnológica os coeficientes associados não são significativos em nenhum dos modelos estimados. 
Os resultados da coluna (12) a (15) da Tabela 3 apresentam os resultados dos modelos com as amostras desagregadas por tipo de parceiro, sendo cadeia produtiva, concorrentes, grupo e instituições de pesquisa, respectivamente. Pelos resultados apresentados na coluna (12), gastos com P\&D, tamanho da empresa, skill, obter informações de instituições de pesquisa e considerar a falta de fontes de financiamento um obstáculo à inovação aumentam a probabilidade de cooperar com empresas da cadeia produtiva no Brasil. Na coluna (13) da Tabela 3 estão os resultados do modelo com empresas que realizam cooperação com concorrentes no país. Os resultados apontam que gastos com P\&D, tamanho das empresas e considerar de alta importância os concorrentes e as instituições de pesquisa como fontes de informação aumenta a probabilidade de cooperar para inovar.

Quanto aos resultados do modelo com empresas que cooperam com grupo no Brasil (coluna 14), verifica-se que ter capital estrangeiro, participar de grupo e obter informações de instituições de pesquisa aumentam a probabilidade de cooperar. Pelos resultados apresentados na coluna (15) da Tabela 3, gastos com P\&D, aumento do tamanho da empresa, skill, apoio do governo e considerar a falta de fontes de financiamento um obstáculo à inovação possuem coeficientes associados positivos e estatisticamente significativos, indicando que essas variáveis aumentam a probabilidade de as empresas realizarem cooperação para inovação com instituições de pesquisa no Brasil. Nesse mesmo sentido, assim como em Henttonen e Hurmelinna-Laukkanen (2014), considerar importante a obtenção de informações de instituições de pesquisa também aumenta a probabilidade de as empresas realizarem cooperação para inovação com essas instituições.

A Tabela 4, apresenta os efeitos marginais dos modelos probabilísticos. Os resultados apresentados na coluna (1) mostram que o aumento de $1 \%$ nos gastos com P\&D aumenta em $2,2 \%$ a probabilidade de as empresas cooperarem para inovação. Os resultados da coluna (2) indicam que o aumento de $1 \%$ nos gastos com P\&D aumenta em 2,4\% a probabilidade de as empresas cooperarem para inovação com empresas da cadeia produtiva. Na coluna (5) verificase que o aumento de $1 \%$ nos gastos com $\mathrm{P} \& \mathrm{D}$ aumenta em 2,8\% a probabilidade de as empresas cooperarem para inovação com instituições de pesquisa.

Pela coluna (11) da Tabela 4 verifica-se que o aumento de $1 \%$ nos gastos com P\&D aumenta em $1,4 \%$ a probabilidade de as empresas cooperarem para inovação no país. Na coluna (12) os resultados indicam que o aumento de 1\% dos gastos com P\&D aumenta em 1,5\% a probabilidade de a empresa cooperar para inovação com empresas da cadeia produtiva no país. Na coluna (12) os resultados sugerem que o aumento de $1 \%$ nos gastos com P\&D aumenta em $0,3 \%$ a probabilidade de cooperação para inovação com concorrentes no país. Já na coluna (15) verifica-se que o aumento de $1 \%$ no gasto com P\&D aumenta em 1,0\% a probabilidade de cooperação para inovação com instituições de pesquisa no Brasil.

Diante do fato de grande parte dos estudos internacionais considerarem a existência de endogeneidade entre a decisão de cooperar e de inovar, a próxima etapa empírica desse estudo estima os quinze modelos já descritos anteriormente com o método do IVprobit considerando a intensidade tecnológica do setor como a variável instrumental dos modelos. De acordo com Okamuro et al (2011) esse pode ser considerado um instrumento adequado, pois está correlacionado com os gastos em P\&D, mas não com a decisão de cooperação para inovação. A Tabela 5, organiza os resultados das estimações dos modelos IVprobit. Ressalta-se que não é possível testar a validade do instrumento utilizado pois a realização de testes de validade de instrumentos só possível quando o número de instrumentos é superior a um. 
Tabela 4

Efeitos Marginais - Modelos Probit

\begin{tabular}{|c|c|c|c|c|c|c|c|c|c|c|c|c|c|c|c|}
\hline & \multicolumn{5}{|c|}{ Cooperação } & \multicolumn{5}{|c|}{ Cooperação no Exterior } & \multicolumn{5}{|c|}{ Cooperação no Brasil } \\
\hline & $\begin{array}{l}\text { Coop } \\
\text { (1) }\end{array}$ & $\begin{array}{l}\text { CoopCad } \\
\text { (2) }\end{array}$ & $\begin{array}{l}\text { CoopConc } \\
\text { (3) }\end{array}$ & $\begin{array}{c}\text { CoopGru } \\
\text { (4) }\end{array}$ & $\begin{array}{c}\text { ConcPesq } \\
(5)\end{array}$ & $\begin{array}{c}\text { CoopExt } \\
\text { (6) }\end{array}$ & $\begin{array}{c}\text { CoopCadExt } \\
\text { (7) }\end{array}$ & $\begin{array}{c}\text { CoopConcExt } \\
(8)\end{array}$ & $\begin{array}{c}\text { CoopGruExt } \\
\text { (9) }\end{array}$ & $\begin{array}{c}\text { CoopPesqExt } \\
(10)\end{array}$ & $\begin{array}{c}\text { CoopBra } \\
(11)\end{array}$ & $\begin{array}{c}\text { CoopCadBra } \\
(12)\end{array}$ & $\begin{array}{c}\text { CoopConcBra } \\
(13)\end{array}$ & $\begin{array}{c}\text { CoopGruBra } \\
(14)\end{array}$ & $\begin{array}{c}\text { CoopPesqBra } \\
(15)\end{array}$ \\
\hline lnGPD & $\begin{array}{c}0,022 * * * \\
(0,008)\end{array}$ & $\begin{array}{c}0,024 * * * \\
(0,008)\end{array}$ & $\begin{array}{c}0,005 \\
(0,004)\end{array}$ & $\begin{array}{c}0,004 \\
(0,003)\end{array}$ & $\begin{array}{c}0,028 * * * \\
(0,007)\end{array}$ & $\begin{array}{c}0,001 \\
(0,003)\end{array}$ & $\begin{array}{c}0,001 \\
(0,002)\end{array}$ & $\begin{array}{c}0,000 \\
(0,000)\end{array}$ & $\begin{array}{c}0,000 \\
(0,000)\end{array}$ & $\begin{array}{c}0,000 \\
(0,000)\end{array}$ & $\begin{array}{c}0,014 * * * \\
(0,005)\end{array}$ & $\begin{array}{c}0,015 * * * * \\
(0,004)\end{array}$ & $\begin{array}{c}0,003 * * \\
(0,001)\end{array}$ & $\begin{array}{c}0,000 \\
(0,000)\end{array}$ & $\begin{array}{c}0,010 * * * \\
(0,003)\end{array}$ \\
\hline $\ln \mathrm{PO}$ & $\begin{array}{l}0,021^{*} \\
(0,11)\end{array}$ & $\begin{array}{c}0,018 \\
(0,029)\end{array}$ & $\begin{array}{c}0,007 \\
(0,005)\end{array}$ & $\begin{array}{l}-0,000 \\
(0,004)\end{array}$ & $\begin{array}{c}0,021 \text { ** } \\
(0,010)\end{array}$ & $\begin{array}{c}0,017^{* * * *} \\
(0,004)\end{array}$ & $\begin{array}{c}0,009 * * * \\
(0,003)\end{array}$ & $\begin{array}{c}0,001 \\
(0,001)\end{array}$ & $\begin{array}{l}0,001 * \\
(0,000)\end{array}$ & $\begin{array}{c}0,004 * * \\
(001)\end{array}$ & $\begin{array}{c}0,028 * * * * \\
(0,007)\end{array}$ & $\begin{array}{c}0,020 * * * \\
(0,005)\end{array}$ & $\begin{array}{c}0,009^{* * * *} \\
(0,002)\end{array}$ & $\begin{array}{c}0,000 \\
(0,000)\end{array}$ & $\begin{array}{l}0,012^{* * *} \\
(0,005)\end{array}$ \\
\hline Skill & $\begin{array}{c}0,016 \\
(0,048)\end{array}$ & $\begin{array}{c}0,038 \\
(0,047)\end{array}$ & $\begin{array}{c}0,018 \\
(0,019)\end{array}$ & $\begin{array}{c}0,017 \\
(0,017)\end{array}$ & $\begin{array}{l}-0,047 \\
(0,050)\end{array}$ & $\begin{array}{c}0,036^{* * * *} \\
(0,012)\end{array}$ & $\begin{array}{c}0,021 * * \\
(0,010)\end{array}$ & - & $\begin{array}{c}0,001 \\
(0,001)\end{array}$ & - & $\begin{array}{c}0,085^{* * * *} \\
(0,018)\end{array}$ & $\begin{array}{c}0,065 * * * \\
(0,014)\end{array}$ & - & - & $\begin{array}{c}0,041 \text { **** } \\
(0,010)\end{array}$ \\
\hline Capest & $\begin{array}{c}0,036 \\
(0,033)\end{array}$ & $\begin{array}{l}0,008 \\
(0,032)\end{array}$ & $\begin{array}{l}-0,019 \\
(0,014)\end{array}$ & $\begin{array}{c}0,223 * * * \\
(0,029)\end{array}$ & $\begin{array}{l}-0,037 \\
(0,030)\end{array}$ & $\begin{array}{c}0,051^{* * * *} \\
(0,017)\end{array}$ & $\begin{array}{c}0,017 \\
(0,012)\end{array}$ & $\begin{array}{l}-0, \overline{00} 4 * \\
(0,002)\end{array}$ & $\begin{array}{c}0,046^{* * * *} \\
(0,014)\end{array}$ & $\begin{array}{l}-0, \overline{0} 00 \\
(0,003)\end{array}$ & $\begin{array}{c}0,020 \\
(0,021)\end{array}$ & $\begin{array}{l}-0,000 \\
(0,016)\end{array}$ & $\begin{array}{l}-0,008 \\
(0,005)\end{array}$ & $\begin{array}{c}0, \overline{0005} \\
(0,005)\end{array}$ & $\begin{array}{c}0,009 \\
(0,014)\end{array}$ \\
\hline Gov & $\begin{array}{c}0,073 * * * \\
(0025)\end{array}$ & $\begin{array}{l}0,060 * * \\
(0,025)\end{array}$ & $\begin{array}{c}0,017 \\
(0,012)\end{array}$ & $\begin{array}{c}0,009 \\
(0,010)\end{array}$ & $\begin{array}{c}0,083 * * * \\
(0,023)\end{array}$ & $\begin{array}{c}0,030 * * * \\
(0,009)\end{array}$ & $\begin{array}{l}0,015^{* * *} \\
(0,007)\end{array}$ & $\begin{array}{c}0,005 \\
(0,003)\end{array}$ & $\begin{array}{l}0,002 * \\
(0,001)\end{array}$ & $\begin{array}{c}0,001 \\
(0,002)\end{array}$ & $\begin{array}{c}0,022 \\
(0,015)\end{array}$ & $\begin{array}{c}0,006 \\
(0,012)\end{array}$ & $\begin{array}{l}-0,009 \\
(0,006)\end{array}$ & $\begin{array}{c}0,000 \\
(0,000)\end{array}$ & $\begin{array}{l}0,025^{* *} \\
(0,010)\end{array}$ \\
\hline Pdcont & $\begin{array}{l}-0,006 \\
(0,037)\end{array}$ & $\begin{array}{c}-0,024 \\
(037)\end{array}$ & $\begin{array}{l}-0,013 \\
(0,020)\end{array}$ & $\begin{array}{c}0,010 \\
(0,015)\end{array}$ & $\begin{array}{c}0,005 \\
(0,037)\end{array}$ & $\begin{array}{c}0,009 \\
(0,015)\end{array}$ & $\begin{array}{c}0,008 \\
(0,011)\end{array}$ & - & $\begin{array}{l}-0,000 \\
(0,002)\end{array}$ & $\begin{array}{l}-0,000 \\
(0,004)\end{array}$ & $\begin{array}{l}-0,016 \\
(0,026)\end{array}$ & $\begin{array}{l}-0,024 \\
(0,023)\end{array}$ & $\begin{array}{l}-0,013 \\
(0,013)\end{array}$ & - & $\begin{array}{l}-0,035^{*} \\
(0,021)\end{array}$ \\
\hline Grupo & $\begin{array}{c}0,135^{* * * *} \\
(0,029)\end{array}$ & $\begin{array}{c}0,088^{* * * *} \\
(0,029)\end{array}$ & $\begin{array}{l}-0,002 \\
(0,013)\end{array}$ & $\begin{array}{c}0,164 \\
(0,022)\end{array}$ & $\begin{array}{c}0,099 * * * \\
(0,029)\end{array}$ & $\begin{array}{c}0,009 \\
(0,012)\end{array}$ & $\begin{array}{l}-0,001 \\
(0,008)\end{array}$ & $\begin{array}{c}0, \overline{0} 000 \\
(0,002)\end{array}$ & $\begin{array}{c}0,001 \\
(0,001)\end{array}$ & $\begin{array}{l}-0,001 \\
(0,002)\end{array}$ & $\begin{array}{c}0,009 \\
(0,018)\end{array}$ & $\begin{array}{c}0,012 \\
(0,015)\end{array}$ & $\begin{array}{c}0,003 \\
(0,006)\end{array}$ & $\begin{array}{c}0, \overline{0} 06 \\
(0,005)\end{array}$ & $\begin{array}{c}0,006 \\
(0,012)\end{array}$ \\
\hline Fcadeia & $\begin{array}{c}0,140 \\
(0,123)\end{array}$ & - & $\begin{array}{l}-0,017 \\
(0,073)\end{array}$ & - & $\begin{array}{c}0,110 \\
(0,118)\end{array}$ & - & - & - & - & - & - & - & - & - & - \\
\hline Fconc & $\begin{array}{l}-0,017 \\
(0,025)\end{array}$ & $\begin{array}{c}0, \overline{0} 32 \\
(0,024)\end{array}$ & $\begin{array}{c}0,165 * * * \\
(0,013)\end{array}$ & $\begin{array}{l}0,0 \overline{1} 7 * \\
(0,009)\end{array}$ & $\begin{array}{l}-0,011 \\
(0,023)\end{array}$ & $\begin{array}{l}-0,010 \\
(0,009)\end{array}$ & $\begin{array}{c}-0,017 * * \\
(0,007)\end{array}$ & $\begin{array}{l}0,006^{*} \\
(0,003)\end{array}$ & $\begin{array}{l}-0, \overline{0} 01 \\
(0,001)\end{array}$ & $\begin{array}{c}0,000 \\
(0,002)\end{array}$ & $\begin{array}{c}0,019 \\
(0,015)\end{array}$ & $\begin{array}{c}0,015 \\
(0,012)\end{array}$ & $\begin{array}{l}0,010 * \\
(0,005)\end{array}$ & $\begin{array}{c}0, \overline{0} 00 \\
(0,000)\end{array}$ & $\begin{array}{c}0, \overline{0} 16 \\
(0,010)\end{array}$ \\
\hline Fpesq & $\begin{array}{c}0,181 * * * * \\
(0,025)\end{array}$ & $\begin{array}{c}0,161 * * * \\
(0,024)\end{array}$ & $\begin{array}{c}0,048 * * * \\
(0,012)\end{array}$ & $\begin{array}{c}0,046 * * * \\
(0,009)\end{array}$ & $\begin{array}{c}0,341 * * * \\
(0,019)\end{array}$ & $\begin{array}{c}0,049 * * * \\
(0,009)\end{array}$ & $\begin{array}{c}0,038 * * * \\
(0,007)\end{array}$ & $\begin{array}{l}0,006^{*} \\
(0,003)\end{array}$ & $\begin{array}{c}0,001 \\
(0,001)\end{array}$ & $\begin{array}{c}0,010 * * * \\
(0,003)\end{array}$ & $\begin{array}{c}0,091 * * * \\
(0,015)\end{array}$ & $\begin{array}{c}0,048 * * * \\
(0,012)\end{array}$ & $\begin{array}{c}0,017 * * * \\
(0,005)\end{array}$ & $\begin{array}{c}0,000 \\
(0,000)\end{array}$ & $\begin{array}{c}0,053 * * * \\
(0,009)\end{array}$ \\
\hline Obsfinan & $\begin{array}{c}0,085 * * * * \\
(0,033)\end{array}$ & $\begin{array}{c}0,072 * * \\
(032)\end{array}$ & $\begin{array}{c}0,014 \\
(0,016)\end{array}$ & $\begin{array}{l}-0,003 \\
(0,012)\end{array}$ & $\begin{array}{c}0,075^{* * *} \\
(0,031)\end{array}$ & $\begin{array}{c}0,031 * * \\
(0,015)\end{array}$ & $\begin{array}{c}0,008 \\
(0,010)\end{array}$ & $\begin{array}{c}0,000 \\
(0,002)\end{array}$ & $\begin{array}{c}0,002 \\
(0,002)\end{array}$ & $\begin{array}{c}0,004 \\
(0,003)\end{array}$ & $\begin{array}{c}0,063 * * * \\
(0,022)\end{array}$ & $\begin{array}{c}0,052 * * * \\
(0,019)\end{array}$ & $\begin{array}{l}0,018^{*} \\
(0,009)\end{array}$ & $\begin{array}{c}0,000 \\
(0,001)\end{array}$ & $\begin{array}{l}0,025^{*} \\
(0,014)\end{array}$ \\
\hline Obsorg & $\begin{array}{l}-0,013 \\
(0,037)\end{array}$ & $\begin{array}{c}0,006 \\
(0,036)\end{array}$ & $\begin{array}{c}0,025 \\
(0,018)\end{array}$ & $\begin{array}{l}-0,002 \\
(0,014)\end{array}$ & $\begin{array}{l}-0,008 \\
(0,034)\end{array}$ & $\begin{array}{l}-0,013 \\
(0,011)\end{array}$ & $\begin{array}{c}-0,019 * * * \\
(0,007)\end{array}$ & $\begin{array}{c}0,007 \\
(0,006)\end{array}$ & $\begin{array}{c}0,002 \\
(0,002)\end{array}$ & $\begin{array}{c}-0,004 * * \\
(0,002)\end{array}$ & $\begin{array}{c}-0,036^{*} \\
(0,020)\end{array}$ & $\begin{array}{l}-0,013 \\
(0,017)\end{array}$ & $\begin{array}{l}-0,006 \\
(0,006)\end{array}$ & $\begin{array}{l}-0,000 \\
(0,000)\end{array}$ & $\begin{array}{l}-0,017 \\
(0,012)\end{array}$ \\
\hline Obsqual & $\begin{array}{c}0,019 \\
(0,036)\end{array}$ & $\begin{array}{c}0,004 \\
(0,035)\end{array}$ & $\begin{array}{l}-0,005 \\
(0,016)\end{array}$ & $\begin{array}{c}0,003 \\
(0,014)\end{array}$ & $\begin{array}{c}0,006 \\
(0,032)\end{array}$ & $\begin{array}{c}0,009 \\
(0,014)\end{array}$ & $\begin{array}{c}0,010 \\
(0,012)\end{array}$ & $\begin{array}{c}0,004 \\
(0,003)\end{array}$ & $\begin{array}{l}-0,001 \\
(0,001)\end{array}$ & $\begin{array}{c}0,006 \\
(0,004)\end{array}$ & $\begin{array}{c}0,018 \\
(0,023)\end{array}$ & $\begin{array}{c}0,009 \\
(0,018)\end{array}$ & $\begin{array}{c}0,001 \\
(0,007)\end{array}$ & $\begin{array}{c}0,000 \\
(0,000)\end{array}$ & $\begin{array}{c}0,019 \\
(0,015)\end{array}$ \\
\hline Obstec & $\begin{array}{l}-0,010 \\
(0,041)\end{array}$ & $\begin{array}{c}0,010 \\
(0,041)\end{array}$ & $\begin{array}{c}0,006 \\
(0,021)\end{array}$ & $\begin{array}{c}0,020 \\
(0,019)\end{array}$ & $\begin{array}{c}0,028 \\
(0,039)\end{array}$ & $\begin{array}{l}-0,008 \\
(0,015)\end{array}$ & $\begin{array}{c}0,006 \\
(0,014)\end{array}$ & $\begin{array}{l}-0,006^{*} \\
(0,003)\end{array}$ & $\begin{array}{l}-0,000 \\
(0,001)\end{array}$ & $\begin{array}{l}-0,002 \\
(0,002)\end{array}$ & $\begin{array}{c}0,010 \\
(0,027)\end{array}$ & $\begin{array}{c}0,000 \\
(0,021)\end{array}$ & $\begin{array}{c}0,015 \\
(0,011)\end{array}$ & $\begin{array}{c}0,000 \\
(0,001)\end{array}$ & $\begin{array}{c}0,012 \\
(0,017)\end{array}$ \\
\hline Obsmerc & $\begin{array}{l}0,039 \\
(0040) \\
\end{array}$ & $\begin{array}{c}0,028 \\
(0,040) \\
\end{array}$ & $\begin{array}{l}-0,004 \\
(0,018) \\
\end{array}$ & $\begin{array}{c}0,015 \\
(0,013) \\
\end{array}$ & $\begin{array}{c}0,043 \\
(0,038) \\
\end{array}$ & $\begin{array}{c}0,022 \\
(0,018) \\
\end{array}$ & $\begin{array}{c}0,013 \\
(0,014) \\
\end{array}$ & $\begin{array}{c}0,006 \\
(0,005) \\
\end{array}$ & $\begin{array}{c}0,002 \\
(0,002) \\
\end{array}$ & $\begin{array}{c}0,009 \\
(0,006) \\
\end{array}$ & $\begin{array}{l}-0,002 \\
(0,025) \\
\end{array}$ & $\begin{array}{c}0,007 \\
(0,021) \\
\end{array}$ & $\begin{array}{c}0,011^{* *} \\
(0,005) \\
\end{array}$ & $\begin{array}{l}-0,000 \\
(0,000) \\
\end{array}$ & $\begin{array}{l}-0,008 \\
(0,014) \\
\end{array}$ \\
\hline Pseudo R2 & 0,086 & 0,077 & 0,18 & 0,35 & 0,192 & 0,189 & 0,166 & 0,273 & 0,387 & 0,256 & 0,135 & 0,129 & 0,167 & 0,399 & 0,142 \\
\hline Log-Like & $-1144,9$ & $-1109,5$ & $-557,6$ & $-431,2$ & $-926,4$ & $-416,8$ & $-306,1$ & $-81,4$ & $-114,9$ & $-114,2$ & $-647,2$ & $-525,4$ & $-181,5$ & $-53,03$ & $-425,6$ \\
\hline $\mathrm{N}^{\circ}$ Obs. & 1827 & 1808 & 1816 & 1801 & 1820 & 1802 & 1772 & 1119 & 1488 & 1456 & 1791 & 1772 & 1465 & 904 & 1791 \\
\hline
\end{tabular}

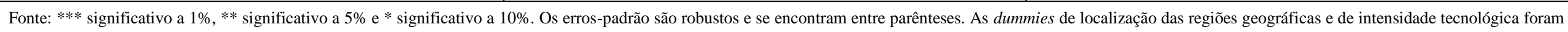
incluídas e não estão reportadas, bem como a constante. Para essas variáveis de regiões geográficas e de intensidade tecnológica os coeficientes associados não são significativos em nenhum dos modelos estimados. 
Ao se observar o Teste Wald na Tabela 5 verifica-se que os modelos de cooperação independente da origem do parceiro (colunas 1 a 5) não indicam a existência de endogeneidade, sendo os resultados obtidos com os modelos probit mais adequados para o entendimento dessa relação. No caso das empresas que cooperam no exterior (colunas 6 a 11) verifica-se a existência de endogeneidade, entretanto, os resultados apresentados nessa tabela mostram-se mais adequados. Verifica-se que os coeficientes associados aos gastos com P\&D são positivos, na maioria dos casos, mas não são significativos. No caso da cooperação com empresas no país, apenas a cooperação com empresas do grupo no país possui endogeneidade e o coeficiente associado aos gastos com P\&D é positivo, mas não é estatisticamente significativo. Esse resultado diverge dos resultados encontrados por Arvanitis e Bolli (2013), em que os efeitos do esforço inovativo afetam com mais intensidade a probabilidade de cooperar com exterior, e com menos intensidade a probabilidade de cooperar com instituições no país. 
Tabela 5

Modelos IVProbit

\begin{tabular}{|c|c|c|c|c|c|c|c|c|c|c|c|c|c|c|c|}
\hline & \multicolumn{5}{|c|}{ Cooperação } & \multicolumn{5}{|c|}{ Cooperação no Exterior } & \multicolumn{5}{|c|}{ Cooperação no Brasil } \\
\hline & $\begin{array}{l}\text { Coop } \\
(1)\end{array}$ & $\begin{array}{c}\text { CoopCad } \\
\text { (2) }\end{array}$ & $\begin{array}{l}\text { CoopConc } \\
\text { (3) }\end{array}$ & $\begin{array}{c}\text { CoopGru } \\
\text { (4) }\end{array}$ & $\begin{array}{c}\text { ConcPesq } \\
\text { (5) }\end{array}$ & $\begin{array}{c}\text { CoopExt } \\
(6)\end{array}$ & $\begin{array}{c}\text { CoopCadExt } \\
(7)\end{array}$ & $\begin{array}{c}\text { CoopConcExt } \\
(8)\end{array}$ & $\begin{array}{c}\text { CoopGruExt } \\
(9)\end{array}$ & $\begin{array}{c}\text { CoopPesqExt } \\
(10)\end{array}$ & $\begin{array}{c}\text { CoopBra } \\
\text { (11) }\end{array}$ & $\begin{array}{c}\text { CoopCadBra } \\
\text { (12) }\end{array}$ & $\begin{array}{c}\text { CoopConcBra } \\
\text { (13) }\end{array}$ & $\begin{array}{c}\text { CoopGruBra } \\
\text { (14) }\end{array}$ & $\begin{array}{c}\text { CoopPesqBra } \\
(15)\end{array}$ \\
\hline $\operatorname{lnGDP}$ & $\begin{array}{l}-0,309 \\
(0,977)\end{array}$ & $\begin{array}{l}-0,219 \\
(0,857)\end{array}$ & $\begin{array}{c}-0,643 \\
(1,346)\end{array}$ & $\begin{array}{c}-0,232 \\
(1,373)\end{array}$ & $\begin{array}{c}-0,227 \\
(1,039)\end{array}$ & $\begin{array}{c}2,090 \\
(2,142)\end{array}$ & $\begin{array}{c}2,289 \\
(2,302)\end{array}$ & $\begin{array}{c}-69,432 \\
(1310,709)\end{array}$ & $\begin{array}{c}0,896 \\
(2,091)\end{array}$ & $\begin{array}{c}2,913 \\
(1,997)\end{array}$ & $\begin{array}{c}-0,022 \\
(1,103)\end{array}$ & $\begin{array}{c}0,467 \\
(1,190)\end{array}$ & $\begin{array}{c}0,075 \\
(1,566)\end{array}$ & $\begin{array}{c}3,059 \\
(2,518)\end{array}$ & $\begin{array}{c}0,683 \\
(1,334)\end{array}$ \\
\hline $\ln \mathrm{PO}$ & $\begin{array}{c}0,333 \\
(0,743)\end{array}$ & $\begin{array}{c}0,263 \\
(0,649)\end{array}$ & $\begin{array}{c}0,573 \\
(1,024)\end{array}$ & $\begin{array}{c}0,210 \\
(1,040)\end{array}$ & $\begin{array}{c}0,301 \\
(0,791)\end{array}$ & $\begin{array}{l}-1,389 \\
(1,622)\end{array}$ & $\begin{array}{l}-1,579 \\
(1,750)\end{array}$ & $\begin{array}{c}53,696 \\
(1010,862)\end{array}$ & $\begin{array}{l}-0,509 \\
(1,609)\end{array}$ & $\begin{array}{l}-1,891 \\
(1,510)\end{array}$ & $\begin{array}{c}0,220 \\
(0,836)\end{array}$ & $\begin{array}{l}-0,137 \\
(0,901)\end{array}$ & $\begin{array}{c}0,241 \\
(1,211)\end{array}$ & $\begin{array}{l}-2,105 \\
(1,865)\end{array}$ & $\begin{array}{c}-0,326 \\
(1,011)\end{array}$ \\
\hline Skill & $\begin{array}{c}0,192 \\
(0,427)\end{array}$ & $\begin{array}{c}0,225 \\
(0,389)\end{array}$ & $\begin{array}{c}0,437 \\
(0,604)\end{array}$ & $\begin{array}{c}0,338 \\
(0,667)\end{array}$ & $\begin{array}{l}-0,011 \\
(0,443)\end{array}$ & $\begin{array}{l}-0,316 \\
(0,962)\end{array}$ & $\begin{array}{l}-0,501 \\
(1.074)\end{array}$ & - & $\begin{array}{c}-0,005 \\
(1,098)\end{array}$ & - & $\begin{array}{c}0,660 \\
(0,537)\end{array}$ & $\begin{array}{c}0,503 \\
(0,573)\end{array}$ & - & - & $\begin{array}{c}0,327 \\
(0,655)\end{array}$ \\
\hline Capest & $\begin{array}{c}0,252 \\
(0,440)\end{array}$ & $\begin{array}{c}0,147 \\
(0,390)\end{array}$ & $\begin{array}{c}0,139 \\
(0,593)\end{array}$ & $\begin{array}{l}1,410 * * \\
(0,610)\end{array}$ & $\begin{array}{c}0,018 \\
(0,450)\end{array}$ & $\begin{array}{l}-0,451 \\
(0,936)\end{array}$ & $\begin{array}{l}-0,736 \\
(1,017)\end{array}$ & $\begin{array}{c}32,494 \\
(622,251)\end{array}$ & $\begin{array}{c}1,247 \\
(1,010)\end{array}$ & $\begin{array}{l}-1,345 \\
(0,958)\end{array}$ & $\begin{array}{c}0,145 \\
(0,481)\end{array}$ & $\begin{array}{l}-0,159 \\
(0,518)\end{array}$ & $\begin{array}{l}-0,226 \\
(0,670)\end{array}$ & $\begin{array}{c}-0,276 \\
(1,148)\end{array}$ & $\begin{array}{l}-0,166 \\
(0,585)\end{array}$ \\
\hline Gov & $\begin{array}{c}0,369 \\
(0,493)\end{array}$ & $\begin{array}{c}0,302 \\
(0,433)\end{array}$ & $\begin{array}{c}0,467 \\
(0,683)\end{array}$ & $\begin{array}{c}0,239 \\
(0,690)\end{array}$ & $\begin{array}{c}0,405 \\
(0,519)\end{array}$ & $\begin{array}{l}-0,710 \\
(1,076)\end{array}$ & $\begin{array}{l}-0,868 \\
(1,142)\end{array}$ & $\begin{array}{c}41,580 \\
(775,869)\end{array}$ & $\begin{array}{c}0,026 \\
(1,049)\end{array}$ & $\begin{array}{l}-1,185 \\
(0,915)\end{array}$ & $\begin{array}{c}0,169 \\
(0,555)\end{array}$ & $\begin{array}{l}-0,132 \\
(0,596)\end{array}$ & $\begin{array}{l}-0,215 \\
(0,790)\end{array}$ & $\begin{array}{l}-1,346 \\
(1,541)\end{array}$ & $\begin{array}{l}-0,051 \\
(0,672)\end{array}$ \\
\hline Pdcont & $\begin{array}{c}0,318 \\
(0,892)\end{array}$ & $\begin{array}{c}0,195 \\
(0,782)\end{array}$ & $\begin{array}{c}0,525 \\
(1,217)\end{array}$ & $\begin{array}{c}0,365 \\
(1,243)\end{array}$ & $\begin{array}{c}0,304 \\
(0,954)\end{array}$ & $\begin{array}{l}-1,803 \\
(1,970)\end{array}$ & $\begin{array}{l}-1,908 \\
(2,090)\end{array}$ & - & $\begin{array}{l}-1,001 \\
(1,886)\end{array}$ & $\begin{array}{c}2,896 \\
(2,040)\end{array}$ & $\begin{array}{c}0,005 \\
(0,995)\end{array}$ & $\begin{array}{l}-0,484 \\
(1,067)\end{array}$ & $\begin{array}{c}-0,247 \\
(1,548)\end{array}$ & $\begin{array}{l}- \\
-\end{array}$ & $\begin{array}{l}-0,818 \\
(1,205)\end{array}$ \\
\hline Grupo & $\begin{array}{c}0,454 \\
(0,308)\end{array}$ & $\begin{array}{c}0,319 \\
(0,281)\end{array}$ & $\begin{array}{c}0,193 \\
(0,431)\end{array}$ & $\begin{array}{c}1,178 * * * \\
(0,444)\end{array}$ & $\begin{array}{c}0,383 \\
(0,334)\end{array}$ & $\begin{array}{l}-0,572 \\
(0,717)\end{array}$ & $\begin{array}{c}-0,724 \\
(0,753)\end{array}$ & $\begin{array}{c}19,333 \\
(365,225)\end{array}$ & $\begin{array}{c}0,002 \\
(0,535)\end{array}$ & $\begin{array}{l}-1,136 \\
(0,765)\end{array}$ & $\begin{array}{c}0,077 \\
(0,363)\end{array}$ & $\begin{array}{c}-0,033 \\
(0,393)\end{array}$ & $\begin{array}{c}0,081 \\
(0,543)\end{array}$ & $\begin{array}{c}0, \overline{4} 74 \\
(0,723)\end{array}$ & $\begin{array}{l}-0,125 \\
(0,441)\end{array}$ \\
\hline Fcadeia & $\begin{array}{c}0,435 \\
(0,387)\end{array}$ & - & $\begin{array}{c}0,026 \\
(0,673)\end{array}$ & - & $\begin{array}{c}0,440 \\
(0,509)\end{array}$ & - & - & - & - & - & - & - & - & - & - \\
\hline Fconc & $\begin{array}{c}-0,051 \\
(0,071)\end{array}$ & $\begin{array}{c}0,079 \\
(0,069)\end{array}$ & $\begin{array}{c}1,207 * * * \\
(0,129)\end{array}$ & $\begin{array}{c}0, \overline{17} 0 \\
(0,112)\end{array}$ & $\begin{array}{l}-0,041 \\
(0,077)\end{array}$ & $\begin{array}{l}-0,055 \\
(0,183)\end{array}$ & $\begin{array}{l}-0, \overline{1} 78 \\
(0,211)\end{array}$ & $\begin{array}{c}4, \overline{2} 14 \\
(69,532)\end{array}$ & $\begin{array}{l}-0, \overline{2} 47 \\
(0,212)\end{array}$ & $\begin{array}{c}0, \overline{1} 35 \\
(0,305)\end{array}$ & $\begin{array}{c}0, \overline{0} 99 \\
(0,088)\end{array}$ & $\begin{array}{c}0, \overline{1} 14 \\
(0,100)\end{array}$ & $\begin{array}{l}0, \overline{27} 2 * \\
(0,159)\end{array}$ & $\begin{array}{c}0, \overline{2} 16 \\
(0,412)\end{array}$ & $\begin{array}{c}0, \overline{1} 68 \\
(0,115)\end{array}$ \\
\hline Fpesq & $\begin{array}{c}0,518 * * * \\
(0,143)\end{array}$ & $\begin{array}{c}0,472 * * * \\
(0,127)\end{array}$ & $\begin{array}{l}0,465 * * \\
(0,209)\end{array}$ & $\begin{array}{c}0,570 * * * \\
(0,208)\end{array}$ & $\begin{array}{c}1,208^{* * * *} \\
(0,163)\end{array}$ & $\begin{array}{c}0,291 \\
(0,341)\end{array}$ & $\begin{array}{c}0,357 \\
(0,379)\end{array}$ & $\begin{array}{c}7,201 \\
(124,395)\end{array}$ & $\begin{array}{c}0,302 \\
(0,361)\end{array}$ & $\begin{array}{c}0,392 \\
(0,525)\end{array}$ & $\begin{array}{c}0,529 * * * \\
(0,173)\end{array}$ & $\begin{array}{l}0,313^{*} \\
(0,180)\end{array}$ & $\begin{array}{c}0,497 \\
(0,325)\end{array}$ & $\begin{array}{c}0,330 \\
(0,520)\end{array}$ & $\begin{array}{c}0,486^{* * *} \\
(0,218)\end{array}$ \\
\hline Obsfinan & $\begin{array}{c}0,272 \\
(0,175)\end{array}$ & $\begin{array}{c}0,231 \\
(0,153)\end{array}$ & $\begin{array}{c}0,210 \\
(0,247)\end{array}$ & $\begin{array}{c}0,005 \\
(0,245)\end{array}$ & $\begin{array}{c}0,269 \\
(0,189)\end{array}$ & $\begin{array}{l}-0,029 \\
(0,393)\end{array}$ & $\begin{array}{l}-0,251 \\
(0,451)\end{array}$ & $\begin{array}{c}16,547 \\
(312,282)\end{array}$ & $\begin{array}{c}0,182 \\
(0,510)\end{array}$ & $\begin{array}{l}-0,355 \\
(0,578)\end{array}$ & $\begin{array}{c}0,318 \\
(0,196)\end{array}$ & $\begin{array}{c}0,272 \\
(0,206)\end{array}$ & $\begin{array}{c}0,375 \\
(0,311)\end{array}$ & $\begin{array}{l}-0,203 \\
(0,697)\end{array}$ & $\begin{array}{c}0,128 \\
(0,242)\end{array}$ \\
\hline Obsorg & $\begin{array}{l}-0,073 \\
(0,142)\end{array}$ & $\begin{array}{l}-0,012 \\
(0,131)\end{array}$ & $\begin{array}{c}0,100 \\
(0,199)\end{array}$ & $\begin{array}{l}-0,056 \\
(0,189)\end{array}$ & $\begin{array}{l}-0,055 \\
(0,139)\end{array}$ & $\begin{array}{c}0,029 \\
(0,315)\end{array}$ & $\begin{array}{l}-0,170 \\
(0,348)\end{array}$ & $\begin{array}{c}-13,394 \\
(261,183)\end{array}$ & $\begin{array}{c}0,424 \\
(0,366)\end{array}$ & $\begin{array}{l}-0,159 \\
(0,487)\end{array}$ & $\begin{array}{l}-0,213 \\
(0,150)\end{array}$ & $\begin{array}{c}-0,068 \\
(0,154)\end{array}$ & $\begin{array}{l}-0,179 \\
(0,307)\end{array}$ & $\begin{array}{c}0,260 \\
(0,665)\end{array}$ & $\begin{array}{c}-0,131 \\
(0,189)\end{array}$ \\
\hline Obsqual & $\begin{array}{c}0,062 \\
(0,103)\end{array}$ & $\begin{array}{c}0,021 \\
(0,101)\end{array}$ & $\begin{array}{c}0,016 \\
(0,149)\end{array}$ & $\begin{array}{c}0,044 \\
(0,153)\end{array}$ & $\begin{array}{c}0,028 \\
(0,106)\end{array}$ & $\begin{array}{c}0,039 \\
(0,253)\end{array}$ & $\begin{array}{c}0,061 \\
(0,293)\end{array}$ & $\begin{array}{c}6,073 \\
(108,749)\end{array}$ & $\begin{array}{l}-0,512 \\
(0,355)\end{array}$ & $\begin{array}{c}0,112 \\
(0,456)\end{array}$ & $\begin{array}{c}0,097 \\
(0,117)\end{array}$ & $\begin{array}{c}0,057 \\
(0,131)\end{array}$ & $\begin{array}{c}0,033 \\
(0,287)\end{array}$ & $\begin{array}{l}-0,053 \\
(0,584)\end{array}$ & $\begin{array}{c}0,158 \\
(0,152)\end{array}$ \\
\hline Obstec & $\begin{array}{l}-0,049 \\
(0,129)\end{array}$ & $\begin{array}{c}0,012 \\
(0,122)\end{array}$ & $\begin{array}{c}0,000 \\
(0,190)\end{array}$ & $\begin{array}{c}0,180 \\
(0,191)\end{array}$ & $\begin{array}{c}0,059 \\
(0,145)\end{array}$ & $\begin{array}{c}0,047 \\
(0,329)\end{array}$ & $\begin{array}{c}0,286 \\
(0,385)\end{array}$ & $\begin{array}{c}-11,395 \\
(200,217)\end{array}$ & $\begin{array}{l}-0,016 \\
(0,474)\end{array}$ & $\begin{array}{c}0,354 \\
(0,630)\end{array}$ & $\begin{array}{c}0,048 \\
(0,151)\end{array}$ & $\begin{array}{c}0,029 \\
(0,171)\end{array}$ & $\begin{array}{c}0,313 \\
(0,322)\end{array}$ & $\begin{array}{c}0,616 \\
(0,733)\end{array}$ & $\begin{array}{c}0,148 \\
(0,196)\end{array}$ \\
\hline Obsmerc & $\begin{array}{c}0,147 \\
(0,171) \\
\end{array}$ & $\begin{array}{c}0,118 \\
(0,168)\end{array}$ & $\begin{array}{c}0,062 \\
(0,249) \\
\end{array}$ & $\begin{array}{c}-0,129 \\
(0,271) \\
\end{array}$ & $\begin{array}{c}0,172 \\
(0,194) \\
\end{array}$ & $\begin{array}{l}-0,134 \\
(0,453) \\
\end{array}$ & $\begin{array}{c}-0,174 \\
(0,488) \\
\end{array}$ & $\begin{array}{c}13,944 \\
(255,011) \\
\end{array}$ & $\begin{array}{c}0,169 \\
(0,476) \\
\end{array}$ & $\begin{array}{c}0,022 \\
(0,575) \\
\end{array}$ & $\begin{array}{c}0,004 \\
(0,219) \\
\end{array}$ & $\begin{array}{c}-0,010 \\
(0,246) \\
\end{array}$ & $\begin{array}{c}-0,374 \\
(0,328) \\
\end{array}$ & $\begin{array}{l}-1,046 \\
(0,912) \\
\end{array}$ & $\begin{array}{c}-0,176 \\
(0,274) \\
\end{array}$ \\
\hline $\begin{array}{l}\text { Wald } \\
\text { Test }\end{array}$ & 0,16 & 0,12 & 0,34 & 0,04 & 0,1 & $3,74^{*}$ & $4,16^{* *}$ & $3,09^{*}$ & 0,27 & $5,49 * *$ & 0,01 & 0,1 & 0 & $3,43^{*}$ & 0,23 \\
\hline $\mathrm{N}^{\circ}$ Obs. & 1827 & 1808 & 1816 & 1801 & 1820 & 1802 & 1772 & 1119 & 1488 & 1456 & 1791 & 1772 & 1465 & 904 & 1791 \\
\hline
\end{tabular}

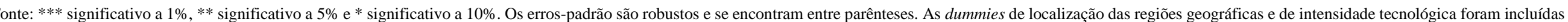

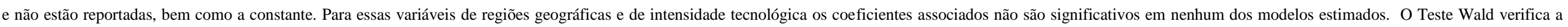
existência de endogeneidade. Os resultados com asterisco indicam a presença de endogeneidade. 


\section{Considerações finais}

Este trabalho realizou uma investigação empírica sobre os determinantes da cooperação para inovação das empresas inovadoras brasileiras com base nos dados da PINTEC 2011 e utilizando como metodologia econométrica a especificação e estimação de modelos probabilísticos. Para tanto investigou-se os determinantes da cooperação para inovação, os determinantes da cooperação para inovação considerando os tipos de parceiros (cadeia produtiva, concorrentes, grupo e instituições de pesquisa); os determinantes da cooperação com o exterior para inovação considerando os tipos de parceiros (cadeia produtiva, concorrentes, grupo e instituições de pesquisa); e os determinantes da cooperação no Brasil para inovação considerando os tipos de parceiros (cadeia produtiva, concorrentes, grupo e instituições de pesquisa).

Em geral, os trabalhos presentes na literatura internacional investigam os determinantes da cooperação para inovação e encontram evidências de que a realização de gastos com $\mathrm{P} \& \mathrm{D}$, o aumento do tamanho da empresa, possuir capital estrangeiro, participar de grupo, receber apoio do governo e aumento da qualificação de mão-de-obra aumentam a probabilidade da empresa cooperar para inovação (Cassiman; Veugelers, 1999, 2002; Negassi, 2004; Okamuro et al., 2010; Kupfer; Avellar, 2009; Faria et al., 2010; Arvanitis; Bolli, 2013).

Dada a escassez de trabalhos empíricos sobre esse tema no país, o trabalho contribui para a literatura em aspectos relevantes, ao investigar os determinantes da cooperação, considerando o tipo de parceiro e a sua localidade (Brasil e exterior). Deste modo, o trabalho avança no debate empírico para as empresas brasileiras em três aspectos, ao investigar: i) os determinantes da cooperação para inovação das empresas brasileiras e se os determinantes da cooperação para inovação das empresas brasileiras são distintos por tipo de parceiro; ii) os determinantes da cooperação com o exterior para inovação das empresas brasileiras e se os determinantes da cooperação com o exterior para inovação das empresas brasileiras são distintos por tipo de parceiro; iii) os determinantes da cooperação no país para inovação das empresas brasileiras e se os determinantes da cooperação no país para inovação das empresas brasileiras são distintos por tipo de parceiro.

Os resultados reportados para a amostra de empresas brasileiras inovadoras sugerem que gastos com $\mathrm{P} \& \mathrm{D}$, características das empresas, apoio do governo, principais fontes de informação utilizadas pelas empresas e obstáculos à inovação explicam a cooperação para inovação. Entretanto, em parte dos modelos especificados, especialmente nos modelos de cooperação com parceiros no exterior, não foram encontradas evidências robustas de que os gastos com P\&D aumentam a probabilidade de cooperação para inovação.

Esse trabalho é um primeiro exercício empírico e possui limitações por se tratar de uma análise considerando apenas uma edição da PINTEC. Pretende-se dar continuidade em investigações futuras, analisando outras edições da PINTEC e utilizando metodologias alternativas, a fim de que os resultados possam contribuir para o desenho das políticas de inovação no país.

\section{Referências bibliográficas}

ARVANITIS, S.; BOLLI, T. A comparison of national and international innovation cooperation in five European Countries. Review of Industrial Organization, v. 43, p. 163-191, 2013. 
BADILLO, E.; GALERA, F. L.; SERRANO, R. M. Cooperation in R\&D, firm size and type of partnership: evidence for the Spanish automotive industry. European Journal of Management and Business Economics, v. 26, n. 1, p. 123-143, 2017.

BELDERBOS, R.; CARREE, M.; LOKSHIN, B. Cooperative R\&D and firm performance. Research Policy, 33, p. 1477-1492, 2005.

CAMERON, A. C.; TRIVEDI, P. K. Microeconometrics Using Stata. Stata Press Publication, United States, 2009.

CASSIMAN, B.; VEUGELERS R. R\&D cooperation and spillovers: some empirical evidence from Belgium. American Economic Review, v. 92, n. 4, p. 1169-1184, Sept. 2002.

CASSIMAN, B.; VEUGELERS, R. In search of complementarity in innovation strategy: internal $\mathrm{R} \& \mathrm{D}$, cooperation in R\&D and external technology acquisition. Management Science, v. 52, n. 1, p. 68-82, Jan. 2006.

COHEN, W.M.; LEVINTHAL, D. A. Innovation and learning: the two faces of R\&D. The Economic Journal, 99, p. 569-596, Sept. 1989.

DE MORAES SILVA, D. R.; FURTADO, A. T.; VONORTAS, N. S. University-industry R\&D cooperation in Brazil: a sectoral approach. Journal of Technology Transfer, v. 43, n. 2, p. 285-315, 2018.

DOSI, G.; CIMOLI, M. De los paradigmas tecnológicos a los sistemas nacionales de producción e innovación. Comercio Exterior, v. 44, n. 8, 1994.

FARIA P.; LIMA, F.; SANTOS, R. Cooperation in innovation activities: the importance of partners. Research Policy, 39, p. 1082-1092, 2010.

FARIA, P.; SCHMIDT, T. International cooperation of innovation: empirical evidence for German and Portuguese Firms. Manheim, 2007. (ZEW Discussion Paper, n. 07-060).

HAGEDOORN, J. Understanding the rationale of strategic technology partnering interorganizational modes of cooperation and sectoral differences. Strategic Management Journal, v. 14, n. 5, p. 371-385, 1993.

HAGEDOORN, J. Inter-firm R\&D partnerships: an overview of major trends and patterns since 1960. MERIT, Faculty of Economics and Business Administration, Maastricht University, 2001.

HENTTONEN, K.; HURMELINNA-LAUKKANEN, E. Determinants of R\&D collaboration: an empirical analysis. International Journal of Innovation Management, v. 18, n. 4, 2014.

KUPFER D.; AVELLAR A. P. Innovation and cooperation: evidences from the Brazilian innovation survey. In: ENCONTRO NACIONAL DE ECONOMIA - ANPEC, 37, Salvador, 2009. Anais...

LUNDVALL, B.-Å. National Systems of Innovation: towards a theory of innovation and interactive learning. Printer Publishers, 1992.

MOWERY, D. C. Collaborative ventures between US and foreign manufacturing firms. Research Policy, v. 18, n. 1, p. 19-33, 1989. 
Ana Paula Macedo de Avellar, Aderbal Oliveira Damasceno, Felipe Queiroz Silva

NEGASSI, S. R\&D co-operation and innovation a microeconometric study on French firms. Research Policy, 33, p. 365-382, 2004.

NELSON, R. R. (Org.). National Innovation Systems: a comparative analysis. 1. ed. New York: Oxford University Press, 1993.

OKAMURO, H.; KATO, M.; HONJO, Y. Determinants of R\&D cooperation in Japanese start-ups. Research Policy, Feb. 2011.

PINHO, M., FERNANDES, A. Relevance of university-industry links for firms from developing countries: exploring different surveys. In: ALBUQUERQUE, E.; SUZIGAN, W.; KRUSS, G.; LEE, K. (Ed.). Developing national systems of innovation: university-industry interactions in the global south. Cheltenham: Edward Elgar Publishing, 2015.

PINTEC. Pesquisa de inovação. Rio de Janeiro: IBGE, 2013.

SCHMIDT, T. Motives for innovation co-operation - Evidence from the Canadian survey of innovation. Manheim, 2007. (ZEW Discussion Paper, n. 07-018).

SCHMIDT, T. Knowledge flows and $R \& D$ co-operation: firm-level evidence from Germany. Manheim, 2005. (ZEW Discussion Paper, n. 05-022).

SUZIGAN, W.; ALBUQUERQUE, E.M. A interação entre universidades e empresas em perspectiva histórica no Brasil. Belo Horizonte: UFMG/Cedeplar, 2008. (Texto para Discussão, n. 329).

SUZIGAN, W.; ALBUQUERQUE, E., CARIO, S. (Ed.). Em busca da inovação: interação universidade-empresa no Brasil. Belo Horizonte: Autêntica, 2011.

TETHER, B. Who co-operate for innovation, and why. An empirical analysis. Research Policy, v. 31, n. 6, p. 947-967, 2002.

VEUGELERS, R.; CASSIMAN, B. Make and buy in innovation strategies: evidence from Belgian manufacturing firms. Research Policy, v. 28, n. 1, p. 63-80, 1999.

VEUGELERS, R.; CASSIMAN, B. R\&D Cooperation between firms and universities. Some empirical evidence from Belgian manufacturing. International Journal of Industrial Organization, 23, p. 355-379, 2005.

WOOLDRIDGE, J. M. Econometric analysis of cross section and panel data. Cambridge, Massachusetts: The MIT Press, 2010. 